\title{
Combined Influences on North American Winter Air Temperature Variability from North Pacific Blocking and the North Atlantic Oscillation: Subseasonal and Interannual Time Scales $\mathscr{O}$
}

\author{
BINHE LUO \\ Key Laboratory of Physical Oceanography/Institute for Advanced Ocean Studies, Ocean University of China and Qingdao \\ National Laboratory for Marine Science and Technology, Qingdao, and CAS Key Laboratory of Regional \\ Climate-Environment for Temperate East Asia, Institute of Atmospheric Physics, Chinese Academy of Sciences, \\ Beijing, China

\section{DEHAI LUO}

CAS Key Laboratory of Regional Climate-Environment for Temperate East Asia, Institute of Atmospheric Physics, Chinese Academy of Sciences, and University of Chinese Academy of Sciences, Beijing, China

\begin{abstract}
Aiguo DAI
Department of Atmospheric and Environmental Sciences, University at Albany, State University of New York, Albany, New York
\end{abstract}

\section{SIMMONDS}

School of Earth Sciences, University of Melbourne, Victoria, Australia

LIXIN WU

Key Laboratory of Physical Oceanography/Institute for Advanced Ocean Studies, Ocean University of China and Qingdao National Laboratory for Marine Science and Technology, Qingdao, China

(Manuscript received 7 May 2019, in final form 31 May 2020)

\begin{abstract}
Winter surface air temperature (SAT) over North America exhibits pronounced variability on subseasonal, interannual, decadal, and interdecadal time scales. Here, reanalysis data from 1950-2017 are analyzed to investigate the atmospheric and surface ocean conditions associated with its subseasonal to interannual variability. Detrended daily SAT data reveal a known warm west/cold east (WWCE) dipole over midlatitude North America and a cold north/warm south (CNWS) dipole over eastern North America. It is found that while the North Pacific blocking (PB) is important for the WWCE and CNWS dipoles, they also depend on the phase of the North Atlantic Oscillation (NAO). When a negative-phase NAO (NAO ${ }^{-}$) coincides with PB, the WWCE dipole is enhanced (compared with the PB alone case) and it also leads to a warm north/cold south dipole anomaly in eastern North America; but when PB occurs with a positive-phase NAO $\left(\mathrm{NAO}^{+}\right)$, the WWCE dipole weakens and the CNWS dipole is enhanced. The PB events concurrent with the NAO ${ }^{-}$ $\left(\mathrm{NAO}^{+}\right)$and SAT WWCE (CNWS) dipole are favored by the Pacific El Niño-like (La Niña-like) sea surface temperature mode and the positive (negative) North Pacific mode. The PB-NAO ${ }^{+}$has a larger component projecting onto the SAT WWCE dipole during the La Niña winter than during the El Niño winter because a more zonal wave train is formed. Strong North American SAT WWCE dipoles and enhanced projections of PB-NAO ${ }^{+}$events onto the SAT WWCE dipole component are also readily seen for the positive North Pacific mode. The North Pacific mode seems to play a bigger role in the North American SAT variability than ENSO.
\end{abstract}

Supplemental information related to this paper is available at the Journals Online website: https://doi.org/10.1175/JCLI-D-19-0327.s1.

Corresponding author: Dr. Dehai Luo, ldh@mail.iap.ac.cn 


\section{Introduction}

Because the North American continent is located between the North Pacific and North Atlantic Oceans, its weather and climate are influenced through atmospheric teleconnections by the ocean conditions, in particular sea surface temperatures (SSTs), in both the Pacific Ocean (Ting and Wang 1997; Wang and Fu 2000; Dai 2013; Dai et al. 2015; Hartmann 2015; Peng et al. 2018, 2019) and the Atlantic Ocean (Mo et al. 2009; Nigam et al. 2011; Overland and Wang 2015). In addition, the recent sea ice declines over Baffin Bay, Davis Strait, and the Labrador Sea also appear to affect North American climate (Chen and Luo 2017, 2019). Recent winter extreme events, such as the 2014 California drought (Wang et al. 2014) and the 2013/14 cold winter over much of North America (Yu and Zhang 2015; Baxter and Nigam 2015), have led to studies investigating the physical processes underlying the recent North American winter climate change (Seager et al. 2007; Lin 2015; Yu et al. 2016; Yu and Lin 2019).

During the 2013/14 winter, intense cold extreme events occurred over most of North America (Wang et al. 2015; Yu and Zhang 2015; Singh et al. 2016; Peng et al. 2018, 2019). This winter was also characterized by a zonal dipole pattern with a warm surface air temperature (SAT) anomaly in western North America and a cold anomaly in eastern North America, which is often referred to as a warm west/cold east (WWCE) dipole pattern (Wang et al. 2015; Singh et al. 2016; Swain et al. 2016; Vigaud et al. 2018). The cause of this SAT dipole pattern has attracted considerable attention (Baxter and Nigam 2015; Yu and Zhang 2015; Hartmann 2015; Lee et al. 2015; Seager et al. 2015; Wang et al. 2015; Singh et al. 2016; Swain et al. 2016; Seager and Henderson 2016; Zaba and Rudnick 2016; Xie and Zhang 2017; Peng et al. 2018, 2019) because severe cold winters over eastern North America have frequently been accompanied by such SAT dipole structures in recent years. For example, Wang et al. $(2014,2015)$ attributed the presence of the WWCE dipole to the prior El Niño and anthropogenic warming. Lee et al. (2015) concluded that anomalously warm Pacific SSTs and low Arctic sea ice concentrations in the Bering Sea might have contributed to the 2013/14 cold winter over North America. Hartmann (2015) attributed the 2013/14 cold winter to El Niño and the North Pacific mode (NPM) of Pacific SSTs, and Peng et al. (2018) also found that the 2014/15 cold winter is linked to the El Niño and NPM. Singh et al. (2016) and Swain et al. (2016) further indicated that the presence of intensified "ridge-trough" wave patterns associated with anthropogenic warming and reduced autumn Arctic sea ice in the East Siberian Sea and Chukcki Sea region is responsible for the North American winter temperature dipole.

Yu and Zhang (2015) found that the severe 2013/14 cold winter in North America is related to the North Pacific Oscillation/west Pacific pattern (NPO/WP), which was also noted in Hartmann (2015). While the previous studies have examined the individual effects from the North Pacific SSTs, it is unknown what types of atmospheric circulation patterns in the broad region from the North Pacific to North Atlantic produce the North American winter SAT dipole pattern in the west-east and north-south directions. Here we address this issue by analyzing observational and reanalysis data from 1950-2017. We propose a new viewpoint that the WWCE dipole in North American winter SAT results from the combined effects of atmospheric blocking over the North Pacific basin and the North Atlantic Oscillation (NAO) over the North Atlantic basin on subseasonal (10-20 day) time scales, whereas its interannual variability is linked to ENSO and NPM through their modulation of the North Pacific blocking (PB) in high latitudes, which concur with different phases of the NAO.

This paper is organized as follows: In section 2, we describe the data and method. Section 3 presents atmospheric circulation patterns linked to the 2010/11 and 2013/14 cold winters and compare their differences to motivate our present study. In section 4 , we present the basic characteristics about the spatial pattern and temporal variability of winter North American SAT using the $k$-mean clustering and empirical orthogonal function (EOF) decomposition methods. A comparison between the clustering technique and EOF method is made, which motivates us to use the EOF analysis to extract the dipole modes of North American SAT. Section 5 describes the connection of the North American winter SAT anomaly patterns to the PB with different phases of NAO. Then, the linkages of the spatial patterns of North American SATs with ENSO and NPM via the changes in the PB and NAO events are further presented in section 6. Conclusions and discussions are summarized in the final section.

\section{Data and method}

We used the monthly and daily data on a $2.5^{\circ} \times 2.5^{\circ}$ grid for winter [December-February (DJF)] from the National Centers for Environmental Prediction-National Center for Atmospheric Research (NCEP-NCAR) reanalysis (Kalnay et al. 1996) for the period from 
December 1950-February 1951 to December 2017February 2018 (simply 1950-2017 hereafter). The data include daily 500-hPa geopotential height (Z500) and SAT (air temperature at $2 \mathrm{~m}$ above Earth's surface). In addition, we also used the winter monthly mean data for SAT over land and SST over ocean (derived from station and marine observations) from the NASA Goddard Institute for Space Studies (GISS) for 1950-2017 (https://data.giss.nasa.gov/gistemp/; Hansen et al. 2010).

We found that the empirical orthogonal function (EOF) patterns and the associated time series of the SAT anomaly from the GISS dataset are highly consistent with those based on the NCEP-NCAR reanalysis data (not shown). Since the daily SAT and geopotential height data are available from the NCEP-NCAR reanalysis, we chose the NCEP-NCAR SAT data to perform our analyses in the following sections.

Winter monthly mean SST data were taken from the Hadley Centre sea surface temperature (HadISST) dataset on a $1^{\circ} \times 1^{\circ}$ grid (Rayner et al. 2003) during DJF 1950/51 to DJF 2017/18 (1950-2017). The individual North Atlantic Oscillation (NAO) and Pacific North American (PNA) patterns events were selected from the daily NAO and PNA index from the NOAA Climate Prediction Center (CPC) (https://www.cpc.ncep.noaa.gov/products/ precip/CWlink/pna/nao.shtml ), which was derived from a rotated EOF (REOF) analysis (Barnston and Livezey 1987). In this paper, the DJF-mean NAO and Arctic Oscillation (AO) index was calculated by making the DJF average of the monthly NAO and AO indices, which are taken from the CPC. The long-term (1950-2017) mean for each calendar day or month was removed from the daily or monthly data to produce the deseasonalized anomaly data, and the linear trend was further removed for the detrended case in some of the analyses.

In this paper, we focus on the variability on subseasonal and interannual time scales. The leading two EOF modes (EOF1 and EOF2) of the detrended winter SST anomalies over the Pacific basin $\left(40^{\circ} \mathrm{S}-60^{\circ} \mathrm{N}, 120^{\circ} \mathrm{E}-90^{\circ} \mathrm{W}\right)$ were used to represent the interannual El Niño-Southern Oscillation (ENSO)-like mode with El Niño and La Niña and North Pacific mode (NPM), when the periods longer than 9 years of the $\mathrm{PC} 1$ and $\mathrm{PC} 2$ time series are filtered out. To further evaluate whether the Pacific SST EOF1 mode reflects ENSO, it is useful to utilize the DJFmean Niño-3.4 index, as defined by the SST anomaly averaged over $170^{\circ}-120^{\circ} \mathrm{W}, 5^{\circ} \mathrm{S}-5^{\circ} \mathrm{N}$, and the DJF-mean Southern Oscillation index (SOI), as defined by the difference of monthly mean sea level pressure SLP at Tahiti and Darwin, taken from the KNMI (Koninklijk Nederlands Meteorologisch Instituut) Climate Explorer (https:// climexp.knmi.nl/selectindex.cgi?id=someone@somewhere).
To identify North Pacific blocking (PB) events, we pick blocking events confined in the longitudinal sector from $170^{\circ}$ to $130^{\circ} \mathrm{W}$ based on the one-dimensional blocking index of Tibaldi and Molteni (1990, hereafter TM). The TM index is defined in terms of the reversal of meridional Z500 gradient: GHGN $=\left[\mathrm{Z} 500\left(\phi_{N}\right)-\mathrm{Z} 500\left(\phi_{o}\right)\right] /\left(\phi_{N}-\phi_{o}\right)$ and GHGS $=\left[\mathrm{Z} 500\left(\phi_{o}\right)-\mathrm{Z} 500\left(\phi_{S}\right)\right] /\left(\phi_{o}-\phi_{S}\right)$ at three given latitudes $\phi_{N}=80^{\circ} \mathrm{N}+\Delta, \phi_{o}=60^{\circ} \mathrm{N}+\Delta$, and $\phi_{S}=40^{\circ} \mathrm{N}+\Delta$, and $\Delta=-5^{\circ}, 0^{\circ}, 5^{\circ}$, where GHGN (GHGS) represents the meridional gradient of Z500 in the anticyclonic (cyclonic) region of blocking. Here, we use $\Delta=-5^{\circ}, 0^{\circ}, 5^{\circ}$ instead of $\Delta=-4^{\circ}, 0^{\circ}, 4^{\circ}$ as used in TM because the daily NCEP-NCAR reanalysis data on a $2.5^{\circ} \times 2.5^{\circ}$ grid are utilized in this paper. Such a treatment does not significantly influence the blocking result, as revealed previously (Diao et al. 2006). A blocking event is defined to have taken place at a given longitude region (within the $170^{\circ}-130^{\circ} \mathrm{W}$ sector) and latitude $\phi_{o}=60^{\circ} \mathrm{N}+\Delta$ if both the conditions GHGS > 0 and GHGN $<-10$ gpm (degrees of latitude) $)^{-1}$ persist at least three consecutive days for at least one of the three values of $\Delta$. Meanwhile, the duration of the $\mathrm{PB}$ is defined here as the number of days for which the above GHGS criterion is satisfied. It is worthy of noting that the mean latitudinal position of the anticyclonic center of the composite PB anomaly is located over the higher latitudes, as noted below.

As in Luo et al. (2017, 2019), we define an individual $\mathrm{NAO}^{+}$or $\mathrm{NAO}^{-}$event to have taken place if the daily NAO index is above 0.5 (referred to as $\mathrm{NAO}^{+}$) or below $-0.5\left(\mathrm{NAO}^{-}\right)$standard deviations (STD) for at least 3 consecutive days. The other NAO events are defined as neutral NAO $\left(\mathrm{NAO}^{0}\right)$ events when the daily index is within -0.5 and 0.5 STDs. The life cycle or the duration of a $\mathrm{NAO}^{+}\left(\mathrm{NAO}^{-}\right)$event is defined to start from the day with a zero value of the daily NAO index, continues to its peak of the positive (negative) daily NAO index, and then declines (increases) to the day with a zero value again when the event ends. An individual PNA event is also defined in a similar form. To explore any links between the PB and NAO, we further define the peak day of the GHGS as the lag 0 day of the PB. When the peak of the GHGS occurs within the life cycle of an $\mathrm{NAO}^{+}\left(\mathrm{NAO}^{-}\right)$ event, we consider the $\mathrm{PB}$ as being related to the $\mathrm{NAO}^{+}$ $\left(\mathrm{NAO}^{-}\right)$event, and refer to it as a $\mathrm{PB}^{-N_{A O}}{ }^{+}$(PB$\mathrm{NAO}^{-}$) event. Similarly, when the $\mathrm{PB}$ is related to an $\mathrm{NAO}^{0}$ event we denote it as a $\mathrm{PB}-\mathrm{NAO}^{0}$ event. In our composite analysis of PB and NAO events and their combined events, the Z500 and SAT anomalies at each grid for periods longer than 9 years excluded are used, which are also applied to the regression and EOF analyses of the Z500 and SAT anomalies. 

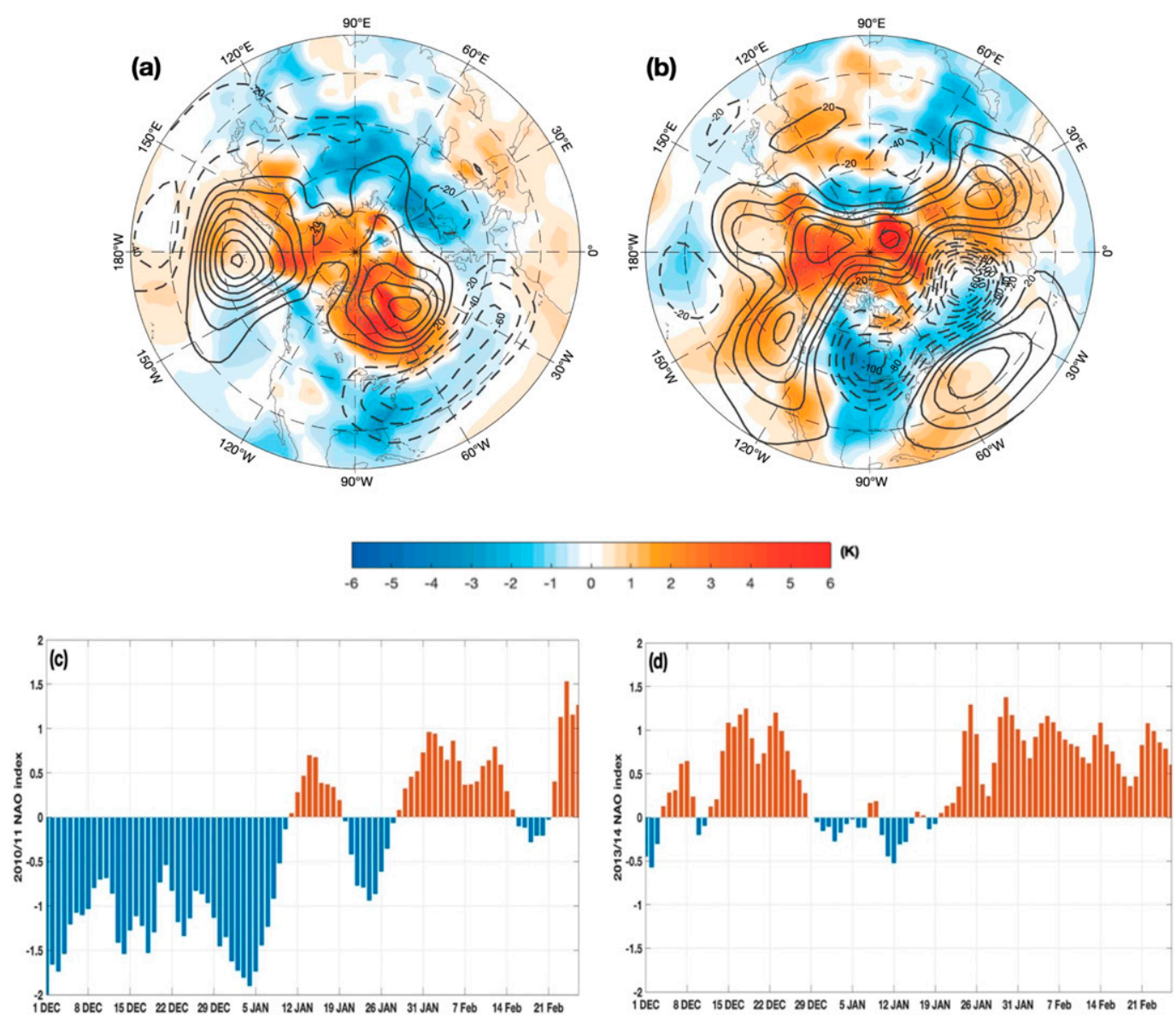

FIG. 1. (top) DJF-mean Z500 (contour interval = 20 gpm) and SAT (color shading) anomalies during the (a) 2010/11 and (b) 2013/14 winters, and (bottom) the time series of daily NAO indices during the (c) 2010/11 and (d) 2013/14 winters.

A two-sided Student's $t$ test is used to examine the statistical significance of the composite anomalies under the assumption of a Gaussian distribution. We also use a Monte Carlo method to examine the statistical significance of the difference of the two series using 10000 simulations.

\section{Atmospheric anomaly circulation patterns during 2010/11 and 2013/14 winters}

Winter North American climates and cold extremes show distinct year-to-year variability (Overland and Wang 2015). For example, the 2013/14 winter was one of the coldest on record in parts of the U.S. Midwest (Minnesota, Wisconsin, Michigan, Iowa, Indiana, Illinois, and Missouri), and it was also one of the driest in the U.S. Southwest from California and Arizona to New Mexico (Yu and Zhang 2015; Singh et al. 2016). Such a North American cold extreme was also found during the 2014/15 winter (Hartmann 2015; Peng et al. 2018). But during the 2010/11 winter, heavy snow and low temperatures mainly occurred over eastern midlatitude North America. While previous studies have examined the physical causes of the 2013/14 and 2014/15 cold winters (Wang et al. 2014; Hartmann 2015; Peng et al. 2018), here we first compare the atmospheric anomaly circulation patterns during these two cold winters to motivate our present study. These different circulation patterns imply that the different North American cold SAT patterns are likely related to the different atmospheric circulation patterns over the North Pacific and North Atlantic basins.

Figures 1a and 1b show the DJF-mean Z500 and SAT anomalies during 2010/11 and 2013/14 winters. For the 2013/14 winter (Fig. 1b), an anticyclonic anomaly appears around the Pacific coasts together with a positive phase NAO $\left(\mathrm{NAO}^{+}\right)$pattern over the North Atlantic and a low-pressure center over the central United States, which is also seen for the 2014/15 winter (not shown). The daily NAO index shows large positive values for most of the days during the 2013/14 winter (Fig. 1d), but large negative values during the early part of the 2010/11 winter and moderate positive values 

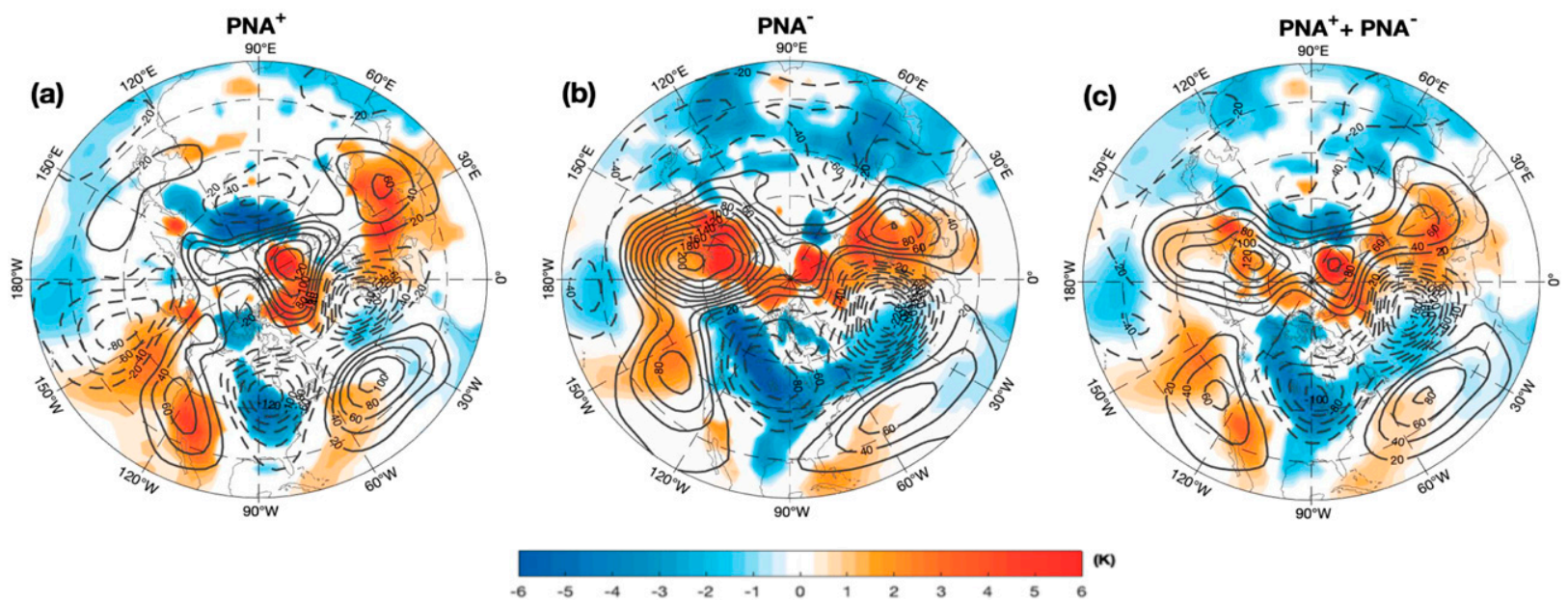

FIG. 2. Time-mean composite daily Z500 and SAT anomalies averaged from lag -10 to 10 days for (a) $2 \mathrm{PNA}^{+}$and (b) $2 \mathrm{PNA}^{-}$events during the 2013/14 winter and (c) $\mathrm{PNA}^{+}$plus $\mathrm{PNA}^{-}$, where the color shading represents the region above the $95 \%$ confidence level for a two-sided Student's $t$ test.

during its later part (Fig. 1c). It is seen that there is a Pacific anticyclonic center located in the Bering Sea and a North Atlantic anticyclonic anomaly over Greenland and its west during the 2010/11 winter, which represent the $\mathrm{PB}$ and $\mathrm{NAO}^{-}$patterns respectively (Fig. 1a). Their combination forms the negative phase of Arctic Oscillation $\left(\mathrm{AO}^{-}\right)$. Clearly, the 2010/11 cold winter is associated with both the $\mathrm{NAO}^{-}$and $\mathrm{NAO}^{+}$ patterns, especially the $\mathrm{NAO}^{-}$. In the two cold winters, the DJF-mean anticyclonic anomalies over the North Pacific and Pacific coasts suggest that PB events on subseasonal time scales must be present, although their positions likely differ.

On the other hand, there are two individual $\mathrm{PNA}^{+}$ and two individual $\mathrm{PNA}^{-}$events during the 2013/14 winters based on the above PNA definition. The timemean composite daily Z500 and SAT anomalies averaged from lag -10 to 10 days (lag 0 denotes the peak day of the daily PNA index) during the PNA life cycle are shown in Figs. $2 \mathrm{a}$ and $2 \mathrm{~b}$ for the $\mathrm{PNA}^{+}$and $\mathrm{PNA}^{-}$ events, whereas Fig. $2 c$ shows their mean Z500 and SAT anomalies. It is found that while the $\mathrm{PNA}^{+}$contributes to the SAT WWCE dipole over North America (Fig. 2a), the $\mathrm{PNA}^{-}$can also have a large contribution to the North American SAT WWCE dipole (Fig. 2b). Thus, the 2013/14 cold winter (Fig. 1b) may be considered as a result of the combined effect of $\mathrm{PNA}^{+}$and $\mathrm{PNA}^{-}$events (Fig. 2c).

In previous studies, the $\mathrm{PNA}^{+}$has been emphasized to play an important role in the 2013/14 cold winter (Harnik et al. 2016), whereas the $\mathrm{PNA}^{-}$was not found to be important. For example, Vigaud et al. (2018) found that the $\mathrm{PNA}^{-}$corresponds to a cold west/warm east (CWWE) SAT dipole over North America (their Figs. 4 and 6) rather than a WWCE dipole because this traditional $\mathrm{PNA}^{-}$does not accompany a high-latitude $\mathrm{PB}$, even though its anticyclonic anomaly is located more west and in lower latitudes. However, as shown by Fig. $2 b$ the $\mathrm{PNA}^{-}$can lead to a WWCE dipole over North America when it is composed of a high-latitude PB combined with an eastward-displaced midlatitude anticyclonic anomaly near the west coast of North America and $\mathrm{NAO}^{+}$. Even for a $\mathrm{PNA}^{+}$, a weak highlatitude $\mathrm{PB}$ and $\mathrm{NAO}^{+}$are still seen (Fig. 2a). This motivates us to examine the combined role of the $\mathrm{PB}$ and NAO in North American SAT variations.

While the SAT anomaly shows a WWCE dipole during the 2010/11 and 2013/14 winters, the cold center of the SAT dipole over the North American east is located farther north during the 2013/14 winter than during the 2010/11 winter. Such a difference leads us to hypothesize that the occurrence region of the SAT cold anomaly depends not only on the presence of PB, but also on the phase of NAO because the negative (positive) Z500 anomaly over the North Atlantic high latitudes can be approximately considered as an $\mathrm{NAO}^{-}$ $\left(\mathrm{NAO}^{+}\right)$pattern. The radiative cooling was shown to play an important role in the formation of the North American cold anomaly (Yu and Zhang 2015). Thus, here we do not examine how atmospheric circulation patterns affect the North American SAT through the radiative cooling or temperature advection. While the differences between the two cold winter patterns are related to the $\mathrm{PB}$ and $\mathrm{NAO}$ and these $\mathrm{PB}$ and NAO events are driven by internal atmospheric processes such as synoptic-scale eddies (Luo 2005; Luo et al. 2007), they are also modulated by the interannual, decadal and 
interdecadal atmospheric variability associated with the SST anomalies in the Pacific and North Atlantic. In this paper, we only examine the variations of North American winter SAT on subseasonal and interannual time scales from a view of the configuration between the $\mathrm{PB}$ and the phase of the NAO. In particular, we investigate under what types of Pacific SSTs the PB-NAO ${ }^{+}$can lead to the SAT WWCE dipole. In contrast, the decadal and interdecadal modulation of SST anomalies in the North Pacific and North Atlantic basins on the North American SAT is not examined here, which will be reported in another paper.

\section{Winter SAT dipole modes over North America}

\section{a. Winter weather regimes over North America}

To identify the weather patterns associated with North American SAT anomalies, we performed a $k$-means clustering analysis (Michelangeli et al. 1995; Vigaud et al. 2018) of North American daily SAT fields with nine regimes. Figure 3 shows the composite daily Z500 and SAT anomalies in winter for nine daily clustering regimes over North America $\left(25^{\circ}-70^{\circ} \mathrm{N}, 140^{\circ}-60^{\circ} \mathrm{W}\right)$ during 1950-2017. It is found that the $\mathrm{C} 4$ anomaly pattern looks like an $\mathrm{AO}^{-}$or $\mathrm{NAO}^{-}$(Fig. 3d). While the $\mathrm{PB}$ is weak in this pattern, the $\mathrm{C} 4$ regime corresponds to a SAT WWCE dipole as seen during the 2010/11 winter. This seems to suggest that the $\mathrm{NAO}^{-}$plays an important role in the SAT WWCE dipole. Furthermore, the C2 (C9) anomaly regime (Figs. 3b,i) resembles the positive (negative) Pacific-North American or $\mathrm{PNA}^{+}$ $\left(\mathrm{PNA}^{-}\right.$) pattern and the $\mathrm{C} 9$ anomaly regime looks like that found in Vigaud et al. (2018), whereas the C1 regime resembles a North Pacific Oscillation/west Pacific (NPO/WP)-like wave train (Fig. 3a) as noted in Baxter and Nigam (2015). The $\mathrm{C} 2$ regime is also seen to result in a SAT WWCE dipole over North America. For the $\mathrm{C} 1$ regime, a strong cold anomaly appears over the middle to low latitudes of North America, although the associated SAT anomaly shows a WWCE SAT dipole. The role of this $\mathrm{C} 1$ regime has been noted in $\mathrm{Yu}$ and Zhang (2015), Hartmann (2015), Harnik et al. (2016), and Vigaud et al. (2018). However, since the $\mathrm{NAO}^{+}$is weak in the $\mathrm{C} 1$ regime, using the $\mathrm{C} 1$ weather pattern cannot reflect the effect of the $\mathrm{NAO}^{+}$on North American SAT because the strong cold SAT anomaly over the North American east during the 2013/14 winter is observed to occur together with a strong $\mathrm{NAO}^{+}$ (Figs. $1 \mathrm{~b}$ and $2 \mathrm{~b}$ ).

Figure 4 shows that the $\mathrm{C} 1, \mathrm{C} 3, \mathrm{C} 5, \mathrm{C} 7$, and $\mathrm{C} 8$ regimes occurred frequently during the 2013/14 winter. Within them, the $\mathrm{C} 3, \mathrm{C} 7$, and $\mathrm{C} 8$ regimes are associated with the $\mathrm{NAO}^{+}$. The combined composite of the daily Z500 and SAT anomalies averaged over the days with the $\mathrm{C} 1, \mathrm{C} 3, \mathrm{C} 5, \mathrm{C} 7$, and $\mathrm{C} 8$ regimes (Fig. 5) can roughly represent the DJF-mean Z500 and SAT anomalies during the 2013/14 winter (Fig. 1b). Thus, the DJF-mean Z500 and SAT anomalies during the 2013/14 winter can be crudely considered as a combination of the $\mathrm{C} 1, \mathrm{C} 3$, C5, C7, and C8 regimes. In other words, the clustering technique cannot unify the PB and NAO into a single regime. Instead, it can subdivide the DJF-mean Z500 anomaly associated with the 2013/14 cold winter into C1, $\mathrm{C} 3, \mathrm{C} 5, \mathrm{C} 7$, and $\mathrm{C} 8$ regimes. However, the EOF analysis used here can avoid this difficulty because the obtained EOF1 (EOF3) mode can better resemble Fig. 1a (Fig. 1b or Fig. 2b), as noted below. Thus, we chose to use the EOF analysis to examine the combined effect of the PB and NAO on North American SAT and establish their linkage with Pacific SST interannual variability. Such an EOF analysis approach has also been widely used in recent studies of North American SAT (Hartmann 2015; Peng et al. 2018). In this paper, our emphasis is to examine the combined effect of the PB and NAO on North American winter SAT, rather than the role of the $\mathrm{C} 1$ regime as examined in Harnik et al. (2016).

\section{b. SAT EOF modes and associated Z500 patterns}

To characterize the North American SAT patterns and their temporal variations, it is useful to perform an EOF analysis of linearly detrended DJF-mean SAT anomalies from 1950-2017 over North America (25ㅇ$\left.70^{\circ} \mathrm{N}, 140^{\circ}-60^{\circ} \mathrm{W}\right)$. The three leading EOFs and their corresponding principal components (PCs) are shown in Figs. 6a-f. EOF1 exhibits a strong WWCE dipole structure (Fig. 6a), while SAT EOF3 shows a cold central and eastern North America and warm Pacific coasts, northern Canada, and the western United States, and overall resembles a cold north/warm south (CNWS) dipole structure over the domain (Fig. 6c). Note that for EOF1 and EOF3, the dipole pattern is reversed [e.g., WWCE would become CWWE and CNWS would become warm-north/cold-south (WNCS)] for years with negative PC values. EOF2 (Fig. 6b) has positive loadings covering most of the domain. Similar EOF results are found for a larger domain $\left(25^{\circ}-70^{\circ} \mathrm{N}, 150^{\circ}-50^{\circ} \mathrm{W}\right)$ as shown in Fig. S1 in the online supplemental material.

Clearly, the winter SAT anomaly patterns in Figs. 6a-c include decadal or interdecadal time scales. To examine the interannual variability of the winter SAT pattern and its linkage with the winter atmospheric circulation pattern associated with the PB with different phases of NAO, the time scales of the winter SAT PC1, $\mathrm{PC} 2$, and $\mathrm{PC} 3$ time series with periods longer than 9 

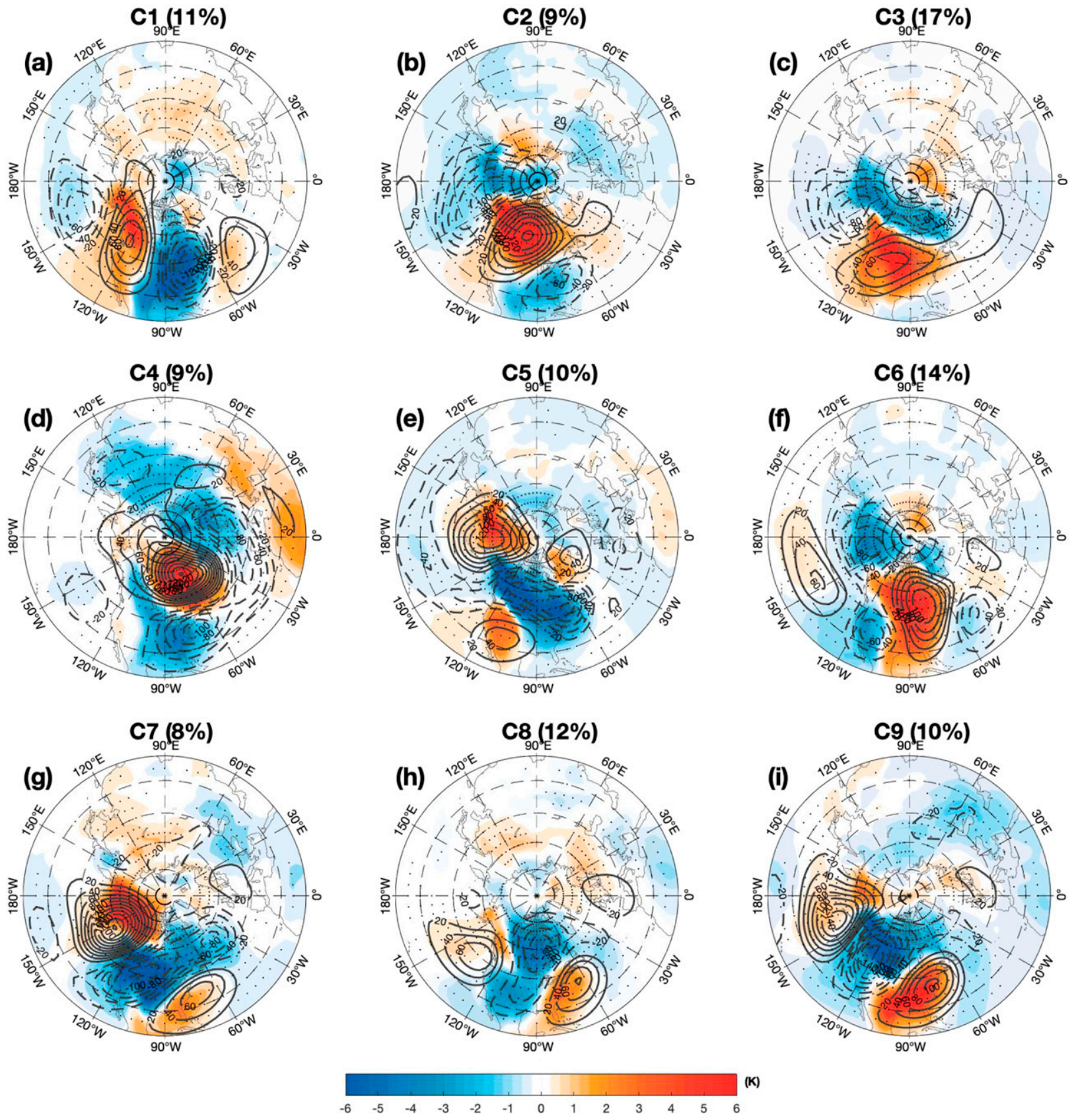

FIG. 3. Composite fields of daily Z500 (contours; interval $=20 \mathrm{gpm}$ ) and SAT (color shading) anomalies for nine daily clustering weather regimes: C1 (701 days), C2 (556 days), C3 (1030 days), C4 (523 days), C5 (614 days), C6 (853 days), C7 (470 days), C8 (747 days), and C9 (643 days) over North America $\left(25^{\circ}-70^{\circ} \mathrm{N}, 140^{\circ}-60^{\circ} \mathrm{W}\right)$ in winter (DJF) during 1950-2017 obtained with a $k$-means clustering analysis (Michelangeli et al. 1995) of Northern Hemispheric winter daily SAT. The black dot represents the regions above the $95 \%$ confidence level based on a two-sided Student's $t$ test.

years are removed to retain their interannual variations. Figures $6 \mathrm{~g}-\mathrm{i}$ show the regression patterns of DJF-mean Z500 and SAT anomalies with interannual time scales (i.e., periods longer than 9 years are excluded) over the Northern Hemisphere (north of $25^{\circ} \mathrm{N}$ ) against the interannual DJF-mean SAT PC1, PC2, and PC3 time series over North America $\left(25^{\circ}-70^{\circ} \mathrm{N}, 140^{\circ}-60^{\circ} \mathrm{W}\right)$. The SAT EOF1 mode corresponds to positive height anomalies centered over the North Atlantic and North Pacific sides of the Arctic (Fig. 6g). This mode consists of an eastward-displaced $\mathrm{PB}$ and an $\mathrm{NAO}^{-}$with a westwardextended negative height anomaly relative to their 

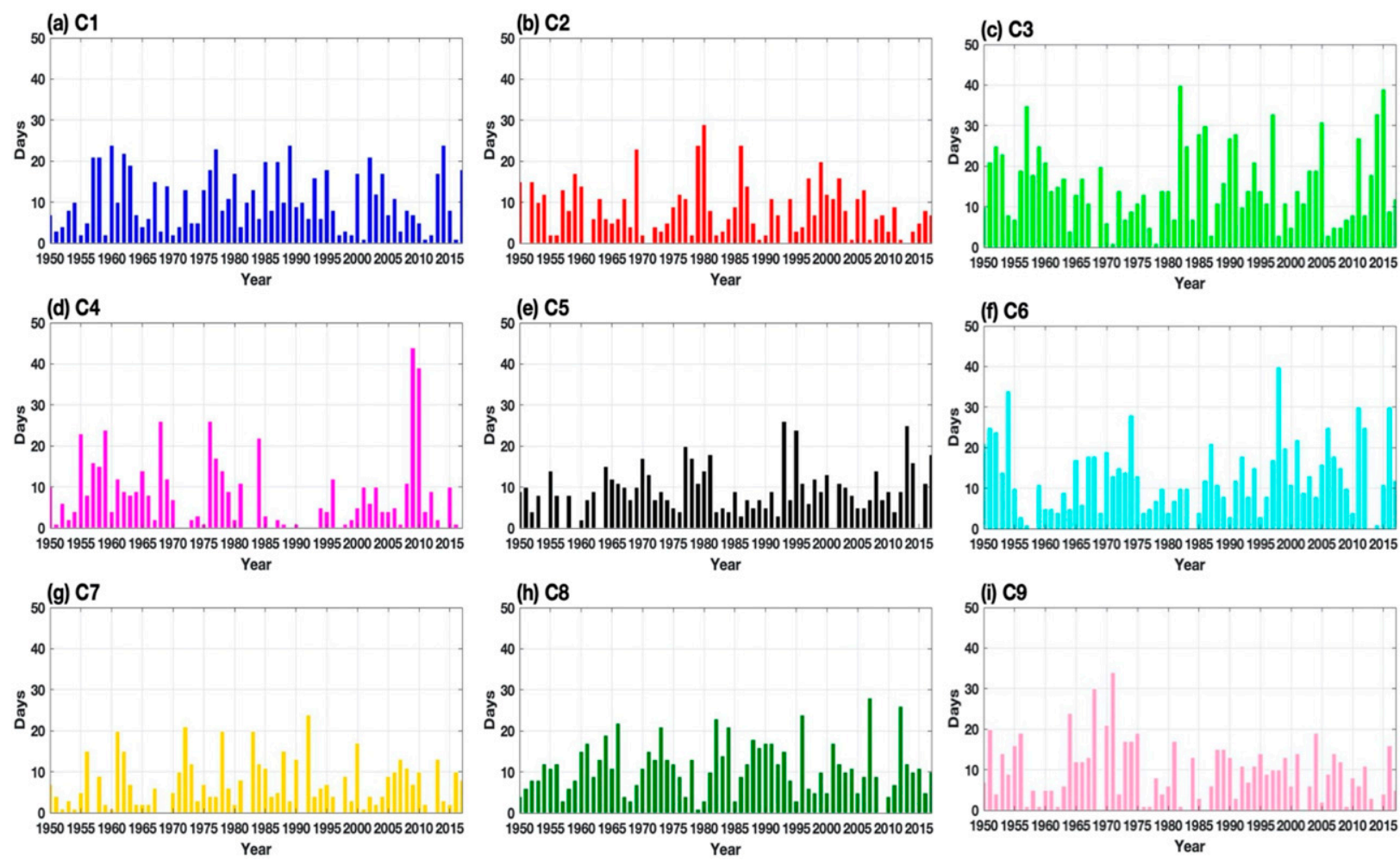

FIG. 4. Time series of the winter day number for each type of the corresponding weather regimes: C1, C2, C3, C4, C5, C6, C7, C8, and C9 of the daily Z500 anomalies during 1950-2017 in Fig. 3.

normal positions and thus favors the formation of a strong WWCE SAT dipole over midlatitude North America. This is a new finding different from previous studies. Broadly speaking, the North Atlantic and Pacific components of the EOF1-related height anomalies form an $\mathrm{AO}^{-}$. Thus, the interannual winter North American SAT anomaly is related to the phase of interannual AO or NAO as revealed from the regressions of interannual DJF-mean Z500 and SAT anomalies against the wintermean $\mathrm{AO}$ and NAO indices without the periods longer than 9 years as shown in Figs. S2c and S2d, while the winter AO index shows a significant positive correlation of $0.49(0.44)(p<0.01)$ with the NAO index for raw (detrended) data (Figs. S2a,b). It is found that a strong winter WWCE SAT dipole can appear over North America for the negative phase of AO or NAO (Figs. S2c,d). Moreover, the correlation calculation reveals that the SAT EOF1, EOF2, and EOF3 modes over North America have significant correlations of -0.34 , 0.40 , and $0.22(p<0.1)$ with the NAO index; also, the SAT WWCE (CNWS) dipole as the SAT EOF1 (EOF3) mode shows a significant negative (positive) correlation of $-0.55(0.33)(p<0.05)$ with the AO index. Thus, one can infer that North American SAT variability is linked to the variability of NAO events. This result is not noted in Hartmann (2015) or Peng et al. (2018, 2019). As found by Chen and Luo (2017, 2019), the westward extended $\mathrm{NAO}^{-}$(or Greenland blocking), which is related to sea ice and SST anomalies in the mid- to high-latitude North Atlantic (Chen and Luo 2019), can lead to enhanced cold anomalies over North America. The stronger correlation of the SAT WWCE and CNWS dipoles with the AO index than with the NAO index suggests that the combined influence from the atmospheric circulation patterns (e.g., PB and NAO) over Pacific and North Atlantic basins on the North American SAT dipoles is likely larger than that from the North Atlantic alone.

Figure $6 \mathrm{~h}$ shows that a warm SAT anomaly over most of North America corresponds to a positive Z500 anomaly over North America (and the North Atlantic) and a negative height anomaly over the North Pacific. In contrast, the Z500 anomaly associated with the SAT EOF3 shows a wave train structure with a positive anomaly over the Bering Sea and western North America and a negative anomaly over eastern North America (Fig. 6i). This large-scale circulation pattern does not resemble a large-scale wave train noted by Lee et al. (2015), Wang et al. (2015), and Singh et al. (2016) during the cold winter of 2013/14. It also differs from both the traditional negative PNA (PNA ${ }^{-}$) (Barnston and Livezey1987) and 


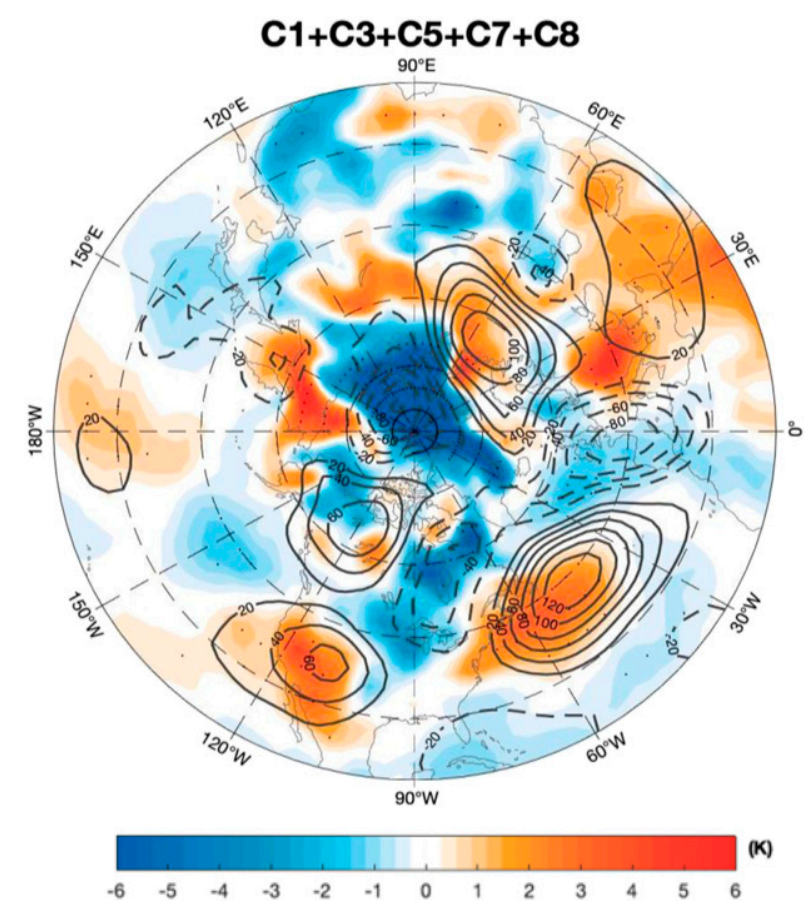

FIG. 5. The combined composite field of the $\mathrm{C} 1, \mathrm{C} 3, \mathrm{C} 5, \mathrm{C} 7$, and C8 regimes within the nine weather patterns of the daily SAT (color) and Z500 (contours) anomalies obtained from a $k$-means clustering analysis of Northern Hemispheric winter daily SAT.

NPO/WP teleconnection patterns (Linkin and Nigam 2008; Baxter and Nigam 2015; Yu and Zhang 2015; Lee et al. 2015; Liang et al. 2017) because the atmospheric teleconnection pattern obtained here comprises a highlatitude $\mathrm{PB}$ and $\mathrm{NAO}^{+}$. To some extent, the interannual variability of the North American SAT is closely related to interannual variations of $\mathrm{PB}, \mathrm{NAO}$, and their combined events. In other words, the interannual variability of the North American SAT can be reflected by the yearto-year change of the winter average of subseasonal North American SAT anomalies associated with the PB events and combined events with NAO.

\section{Impact of Pacific blocking and NAO on North American SAT}

In this section, we examine how the $\mathrm{PB}$ events and combined events with NAO influence the spatial patterns of subseasonal North American SAT anomalies to establish a linkage of the winter North American SAT change with the $\mathrm{PB}$ events and combined events with NAO.

\section{a. Effect of individual $P B$ and $N A O$ events}

Here, we first calculated the number of individual PB and $\mathrm{NAO}$ events in each winter to examine the influence of individual PB or NAO events on the North American
SAT anomaly. The time series of the event number of individual PB or NAO events during 1950-2017 are shown in Figs. $7 \mathrm{a}-\mathrm{c}$. It is seen that there are more PB events during 1980-2000 (Fig. 7a), more $\mathrm{NAO}^{+}$events during 1985-2005 (Fig. 7b), and more $\mathrm{NAO}^{-}$events during 1955-70 (Fig. 7c) than other years. The time series of the $\mathrm{PB}$ events is correlated with the $\mathrm{PC}$ of both the SAT EOF1 (WWCE dipole) $(r=0.29, p<0.1)$ and EOF3 (CNWS dipole) $(r=0.22, p<0.1)$, but not with the SAT EOF2 mode. Thus, the presence of PB can contribute to the North American SAT dipole.

Since the individual PB and NAO events have the lifetimes with a period of 10-20 days, it is instructive to show the time-mean composite daily Z500 and SAT anomalies averaged from lag -10 to 10 days (where lag 0 denotes the peak day of the PB or NAO) in Figs. 7d-f for $\mathrm{PB}, \mathrm{NAO}^{+}$, and $\mathrm{NAO}^{-}$events using the $\mathrm{Z500}$ and SAT anomaly fields on interannual time scales without periods longer than 9 years. In Figs. $7 \mathrm{~d}-\mathrm{f}$, the difference between the two of the three composite anomalies is statistically significant $(p<0.05)$ (not shown). The composite Z500 anomaly field of PB events (Fig. 7d) shows a large positive height anomaly over the Pacific high-latitude region (Bering Sea and Alaska), as expected, and a weak negative height anomaly over eastern North America, together with a cold anomaly from western Canada to eastern North America (Fig. 7d). Weak cold anomalies over midlatitude eastern North America are associated with $\mathrm{NAO}^{-}$events (Fig. 7f), whereas $\mathrm{NAO}^{+}$corresponds to strong cold anomalies over high-latitude eastern North America (Fig. 7e). These results suggest that the spatial structure of the North American SAT anomaly depends on the phase of NAO as well as the PB.

The SAT anomaly patterns for the two phases of NAO (Figs. 7e,f) may include the effect of any concurrent $\mathrm{PB}$ events. To emphasize the effect of NAO events without PB, in Fig. 8 we show the time-mean composite Z500 and SAT anomalies averaged from lag -10 to 10 days of the individual $\mathrm{NAO}^{+}$and $\mathrm{NAO}^{-}$events that do not have a concurrent PB. Their difference is also statistically significant (not shown). The cold anomaly over eastern North America in Fig. 7f largely disappears for the $\mathrm{NAO}^{-}$without PB (Fig. 8b), whereas the highlatitude cold anomaly for the $\mathrm{NAO}^{+}$events is still present (Fig. 8a). In other words, the $\mathrm{NAO}^{+}$or $\mathrm{NAO}^{-}$ events alone cannot produce the cold anomaly over midlatitude North America when the PB is absent, unless the $\mathrm{NAO}^{-}$or $\mathrm{NAO}^{+}$moves westward under the condition of a large sea ice decline in the North Atlantic high latitudes as noted by Chen and Luo $(2017,2019)$. However, the situation changes once the PB occurs together with the NAO. 

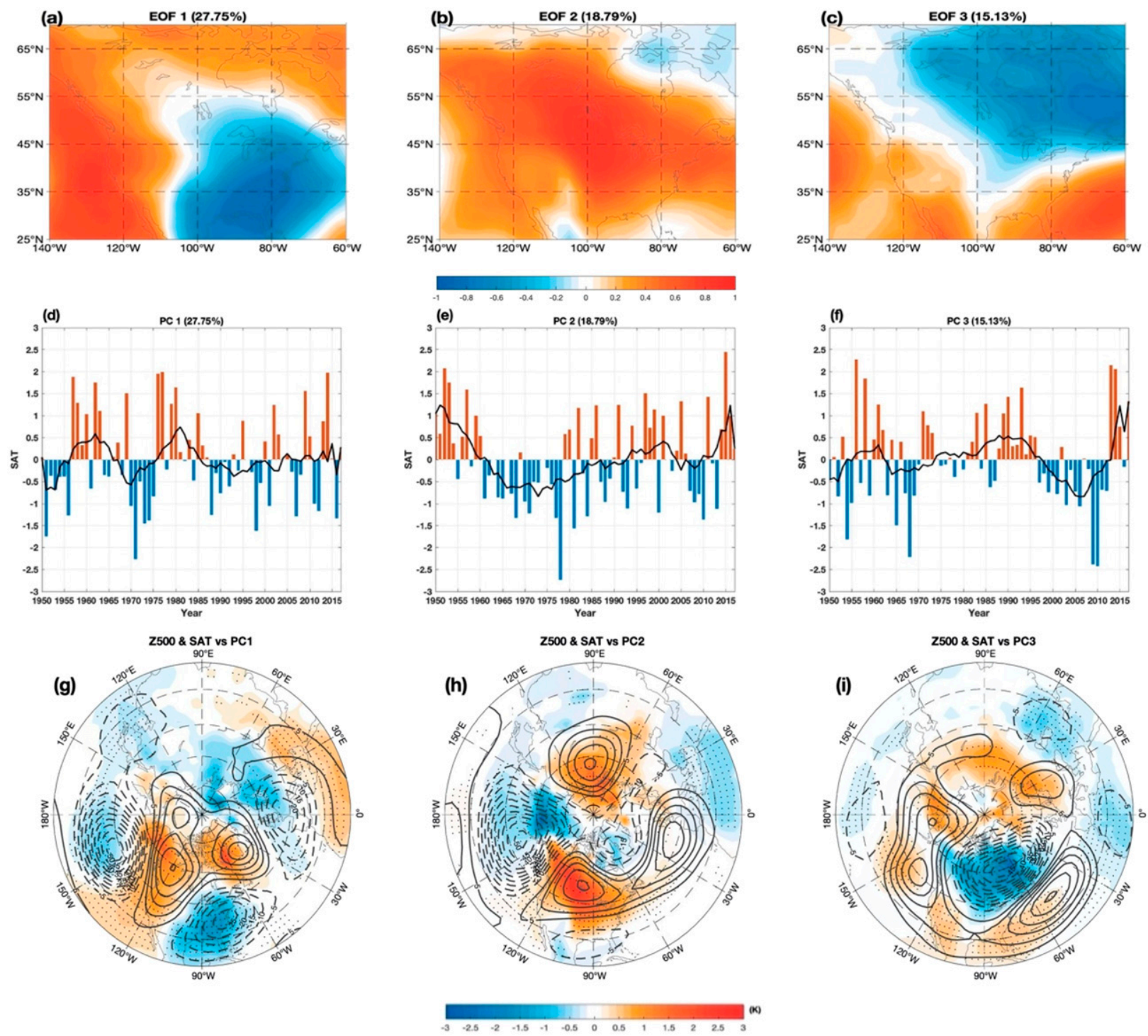

FIG. 6. (a)-(c) First, second, and third leading empirical orthogonal function (EOF1, EOF2, and EOF3) modes of DJF-mean SAT anomaly over North America $\left(25^{\circ}-70^{\circ} \mathrm{N}, 140^{\circ}-60^{\circ} \mathrm{W}\right)$, and (d)-(f) time series of their corresponding principal components (PC1, PC2, and PC3). (g)-(i) Regression patterns of interannual DJF-mean Z500 (contours) and SAT (color shading) anomalies over the Northern Hemisphere (north of $25^{\circ} \mathrm{N}$ ) against the (g) PC1, (h) PC2 and (i) PC3 time series of interannual DJF-mean SAT anomaly over North America for detrended data during 1950-2017. The black line in Figs. 6d-f represents a 9-yr smoothing curve. In (g)-(i), the dot represents the region above the $95 \%$ confidence level for a two-sided Student's $t$ test.

\section{b. Impacts of different configurations of the $P B$ and $N A O$}

The above analysis indicates that different combinations of the PB with the different phases of NAO are likely more important for the North American SAT change than the PB or NAO alone. Here we further examine this issue. We first calculated the number of the PB-NAO ${ }^{+}, \mathrm{PB}^{-N A O}{ }^{-}$, and $\mathrm{PB}-\mathrm{NAO}{ }^{0}$ events (see section 2 for their definition) in each winter and the results are shown in Figs. 9a-c. The PB-NAO ${ }^{+}$events are frequent during 1980-2000 and relatively infrequent during 1956-70 and 2001-10 (Fig. 9a). The PB-NAO ${ }^{-}$ events are frequent during 1955-70, 1975-90, and 19952010 (Fig. 9b), whereas the PB-NAO ${ }^{0}$ events are frequent mainly during 1960-80 (Fig. 9c). The top part of Table 1 shows that $\mathrm{PB}-\mathrm{NAO}^{-}$events are correlated with the three SAT EOFs, especially EOF1 (WWCE dipole) $(r=$ $0.42, p<0.01)$, while the $\mathrm{PB}-\mathrm{NAO}^{+}$events are correlated only with the SAT EOF3 (CNWS dipole) $(r=0.58, p<$ 0.01 ), and the PB-NAO ${ }^{0}$ events are weakly correlated only with the SAT EOF1 $(r=0.22, p<0.1)$. When the 

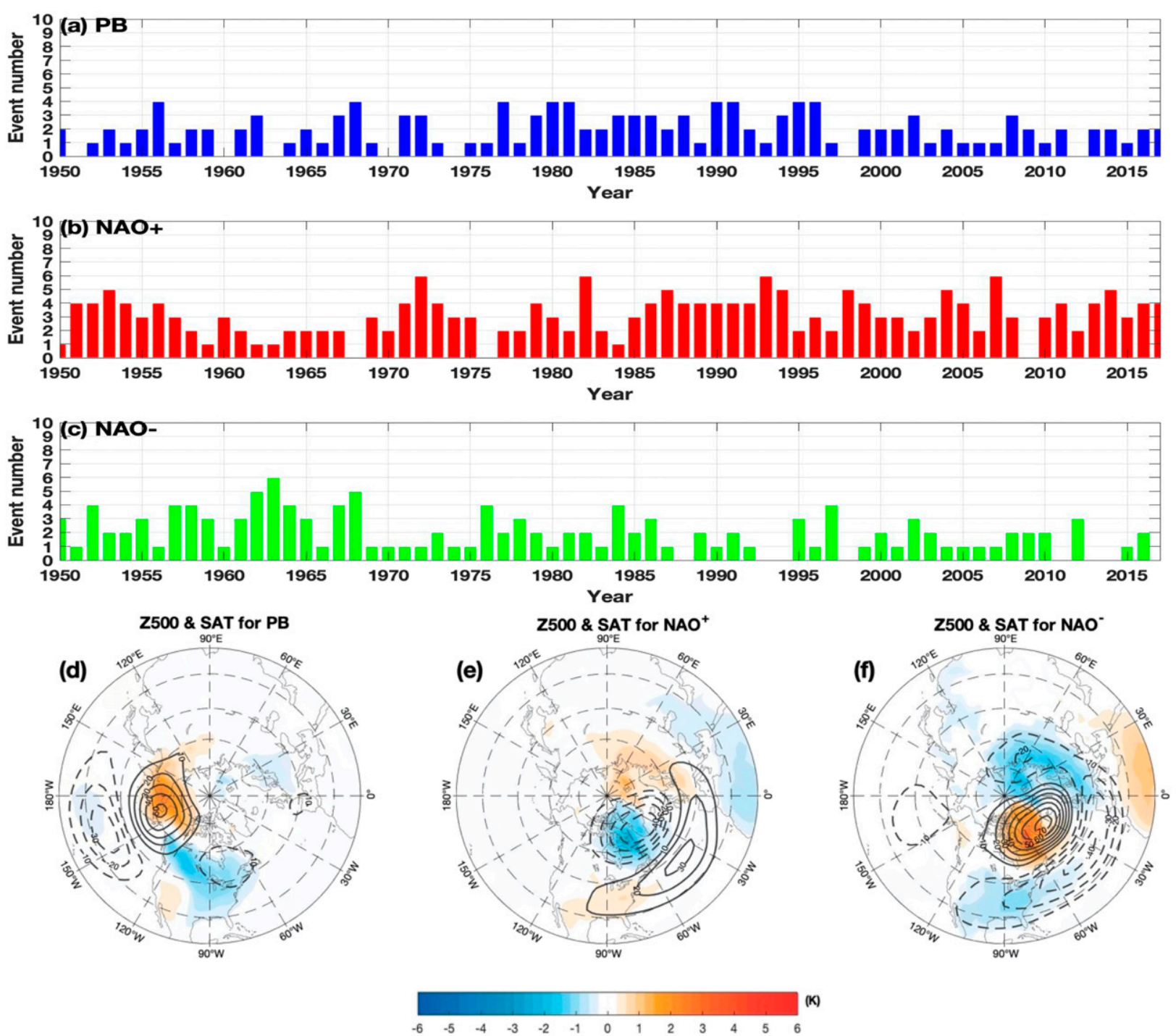

FIG. 7. Time series of the (a) North Pacific blocking (PB), (b) $\mathrm{NAO}^{+}$, and (c) NAO ${ }^{-}$events in winter (DJF) during 1950-2017, and timemean composite daily Z500 and SAT anomalies averaged from lag -10 to 10 days for all (d) $\mathrm{PB}$, (e) $\mathrm{NAO}^{+}$, and (f) $\mathrm{NAO}^{-}$events, where lag 0 denotes the day of the PB peak in (d) or the NAO peak in (e) and (f). The color shading represents the regions above the $95 \%$ confidence level based on a two-sided Student's $t$ test.

time scales longer than 9 years are removed, the PB$\mathrm{NAO}^{-}$events are correlated with the EOF1 (WWCE dipole) $(r=0.31, p<0.05)$ and EOF3 (CNWS dipole) $(r=-0.32, p<0.05)$ modes, whereas the PB-NAO ${ }^{+}$ events are correlated with the SAT EOF3 (CNWS dipole) $(r=0.51, p<0.01)$ as shown in Table 1 (bottom).

Visual comparisons between the PCs shown in Figs. $6 \mathrm{~d}-\mathrm{f}$ and the time series shown in Figs. 9a-c also revealed some correspondence between the SAT PC variations and the combined $\mathrm{PB}$ and NAO events. Thus, some of the variations (including decadal changes) in North American SAT shown in Fig. 3 are likely linked to the changes in the PB-NAO ${ }^{+}$and $\mathrm{PB}-\mathrm{NAO}^{-}$events.
The Z500 anomaly of the concurring $\mathrm{PB}$ and $\mathrm{NAO}^{+}$ events (Fig. 9d) shows a large-scale high-latitude wave train which differs from the traditional $\mathrm{PNA}^{-}$pattern. The North American cold anomaly is stronger and shifts farther southward for the PB-NAO ${ }^{+}$(Fig. 9d) than for the $\mathrm{NAO}^{+}$without PB (Fig. 8a) because their differences are statistically significant (not shown). This SAT anomaly structure behaves as a CNWS dipole pattern over eastern North America. For this case, severe cold winters may occur over eastern North America and its high-latitude region (the Great Lakes, the Great Plains, northeast Canada, and western Greenland). The SAT CNWS dipole is not purely meridional and has a weak 


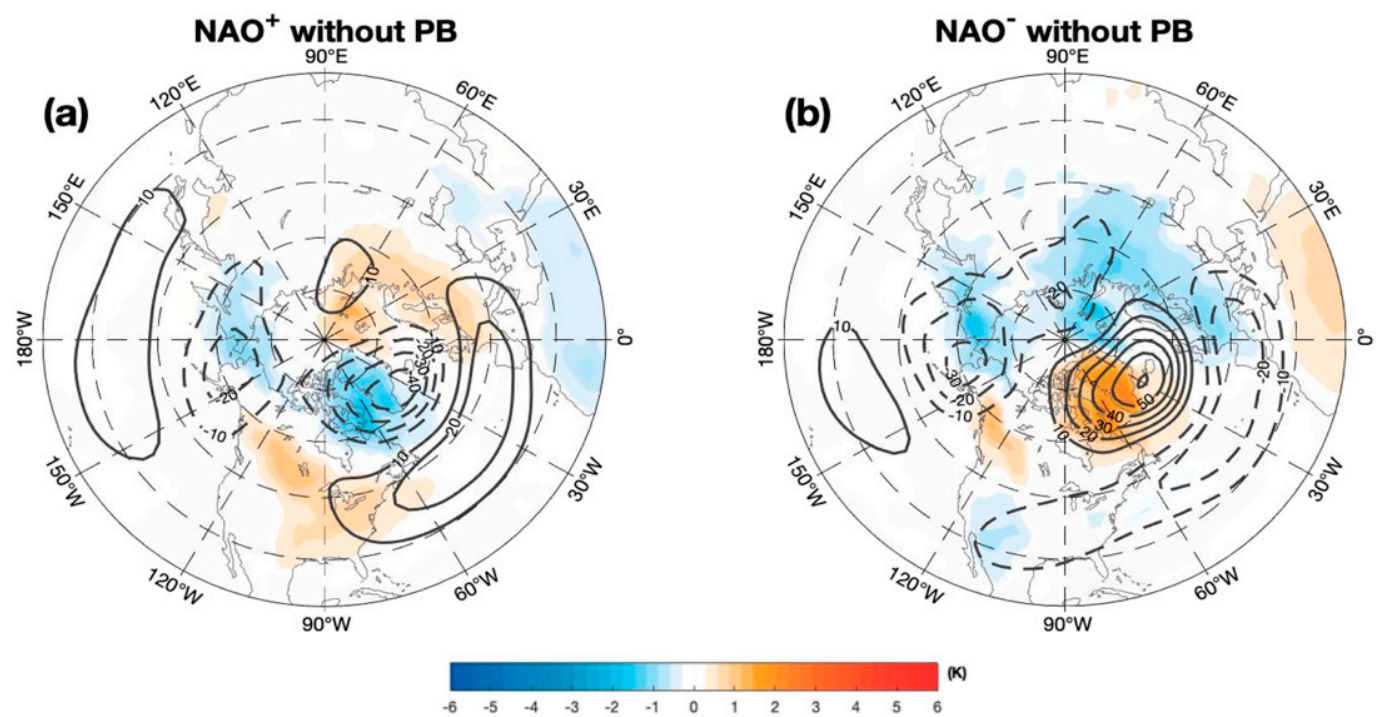

FIG. 8. Time-mean composite daily Z500 and SAT anomalies of the (a) $\mathrm{NAO}^{+}$and (b) $\mathrm{NAO}^{-}$events without PB averaged from lag -10 to 10 days during 1950-2017 winters, where lag 0 denotes the peak day of the NAO. The color shading represents the regions above the 95\% confidence level based on a two-sided Student's $t$ test.

zonal dipole component with a warm anomaly over western North America from California to Mexico and a cold anomaly over the higher-latitude region of eastern North America or a weak WWCE dipole component. For the $\mathrm{PB}_{-} \mathrm{NAO}^{-}$cases (Fig. 9e), the SAT pattern exhibits a typical WWCE dipole structure in midlatitude North America, while the PB alone can only produce a weak zonal SAT dipole anomaly (Fig. 9f). Thus, amplified cold anomalies can appear over the central and eastern parts of midlatitude North America and the high latitudes of western North America when the PB occurs together with the $\mathrm{NAO}^{-}$. This suggests that the occurrence of winter cold extremes over North America depends not only on the presence of $\mathrm{PB}$, but also on the phase of the NAO.

\section{c. Temporal evolution of the SAT WWCE and CNWS dipoles}

Here, we further quantify the temporal evolutions of the daily North American SAT WWCE and CNWS dipoles for PB-NAO ${ }^{+}, \mathrm{PB}^{-N A O}{ }^{-}$, and PB-NAO ${ }^{0}$ events. Before doing this, we first define $T_{W E}=T_{W}-T_{E}$ as an index characterizing the strength of the SAT WWCE dipole, where $T_{W}$ and $T_{E}$ denote the domain average of the daily SAT anomalies over western and eastern North America as defined by the regions $25^{\circ}-50^{\circ} \mathrm{N}$, $130^{\circ}-103^{\circ} \mathrm{W}$ and $25^{\circ}-50^{\circ} \mathrm{N}, 103^{\circ}-65^{\circ} \mathrm{W}$, respectively. Similarly, $T_{N S}=T_{N}-T_{S}$ reflects the strength of the CNWS dipole, where $T_{S}$ is taken here to be the same as $T_{E}$, and $T_{N}$ is the domain average of the daily SAT anomalies over northeastern North America $\left(50^{\circ}-70^{\circ} \mathrm{N}\right.$, $\left.103^{\circ}-65^{\circ} \mathrm{W}\right)$. The time series of the composite daily $T_{W E}$ and $T_{N S}$ indices (averaged over all such events) are shown in Fig. 10 for the PB-NAO ${ }^{+}, \mathrm{PB}^{-N A O}{ }^{-}$, and $\mathrm{PB}-$ $\mathrm{NAO}^{0}$ events. Figure $10 \mathrm{a}$ shows that the $T_{W E}$ index is positive and changes with the $\mathrm{PB}$ evolution from lag -2 to +14 days when NAO is neutral (green line in Fig. 10a), indicating that a WWCE dipole can occur over midlatitude North America when the PB occurs even without concurrent NAO. This SAT dipole has a stronger amplitude and a longer duration when the $\mathrm{PB}$ concurs with $\mathrm{NAO}^{-}$events (red line in Fig. 10a). This means that the WWCE dipole is amplified and its duration is lengthened when the $\mathrm{PB}$ occurs together with the $\mathrm{NAO}^{-}$. As a result, intense severe cold extremes are more likely to occur over the midlatitudes of eastern North America. In contrast, the $T_{W E}$ index has a smaller amplitude and a shorter duration for $\mathrm{PB}-\mathrm{NAO}^{+}$(blue line in Fig. 10a) than for PB-NAO ${ }^{0}$ events, implying that the presence of $\mathrm{NAO}^{+}$reduces the $\mathrm{PB}$-induced WWCE dipole and thus suppresses the occurrence of severe cold extremes over midlatitude North America. However, as noted below the PB-NAO ${ }^{+}$can have a relatively large component projecting onto the SAT WWCE dipole under the influence of the Pacific SST anomaly. The Pacific SST condition favoring the SAT WWCE dipole associated with the $\mathrm{PB}-\mathrm{NAO}^{+}$will be further examined in the following section.

Figure 10b shows that the CNWS pattern occurs only during the $\mathrm{PB}-\mathrm{NAO}^{+}$events, and the pattern becomes a 

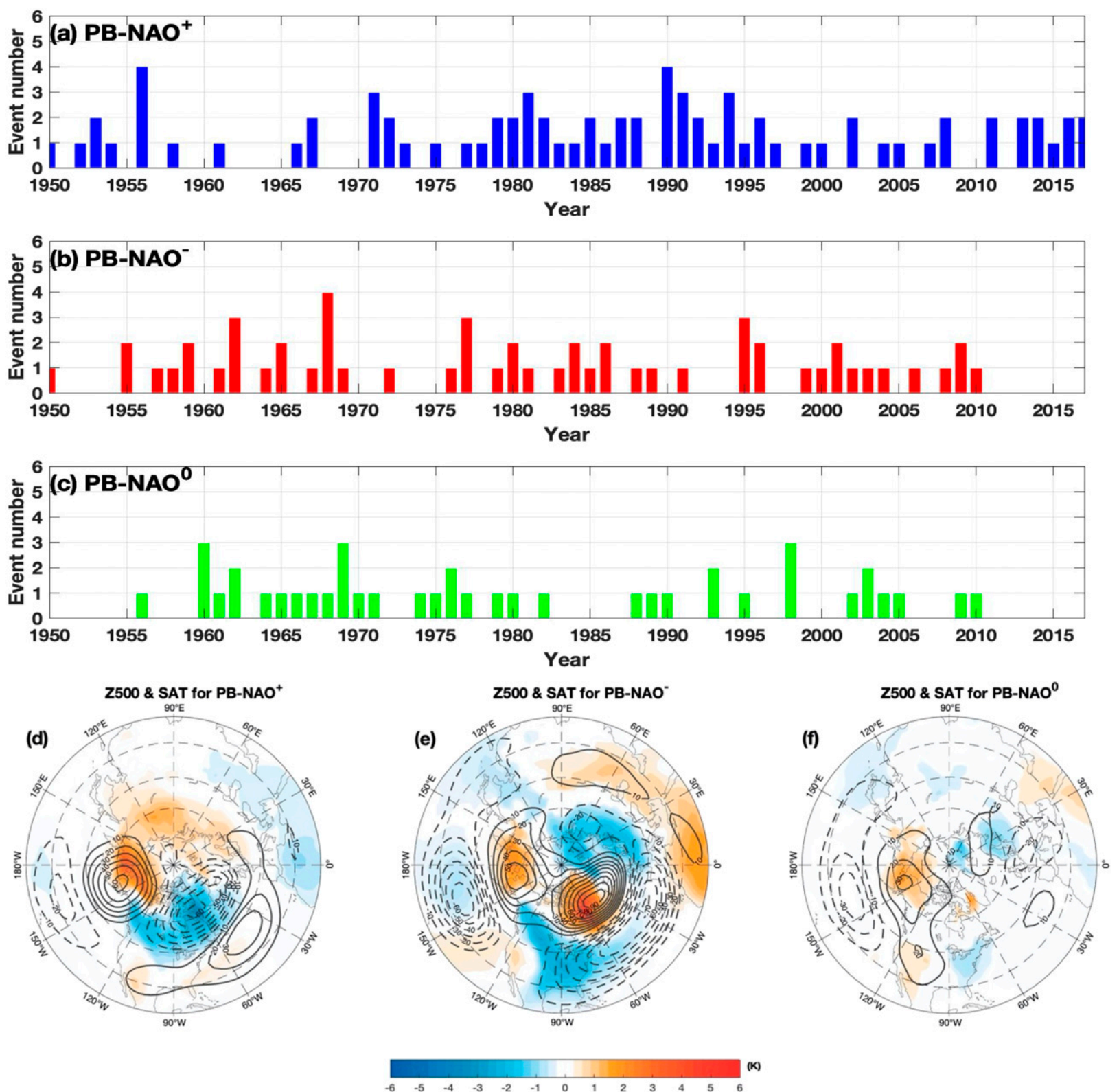

FIG. 9. Time series of the number of the (a) PB-NAO ${ }^{+}$, (b) PB-NAO ${ }^{-}$, and (c) PB-NAO ${ }^{0}$ events during 1950-2017 winters, and time-

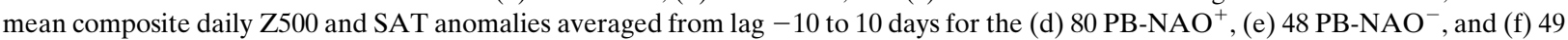
PB-NAO ${ }^{0}$ events, where lag 0 denotes the day of the PB peak. The color shading represents the regions above the $95 \%$ confidence level based on a two-sided Student's $t$ test.

warm-north/cold-south anomaly during the $\mathrm{PB}^{\mathrm{N} A \mathrm{O}^{-}}$ events. When PB occurs without NAO, this SAT pattern becomes weak (green line in Fig. 10b). Figure 10 shows that the North American SAT patterns are much more pronounced and vary more with the $\mathrm{PB}$ for the $\mathrm{PB}$ $\mathrm{NAO}^{-}$case than the other two cases. Thus, cold temperatures over central and eastern North America midlatitudes are likely to be more intense when the $\mathrm{PB}$ concurs with $\mathrm{NAO}^{-}$than the other cases.

\section{North American SAT patterns and their linkages to ENSO-like mode and North Pacific mode}

\section{a. SST EOF patterns}

To investigate a possible connection of North American SAT patterns to the SSTs, Fig. 11 shows the regression patterns of the interannual DJF-mean SST anomalies against the PC1, PC2, and PC3 time series of the detrended interannual DJF-mean North American SAT. 
TABLE 1. Correlation coefficients between the time series of the PB-NAO ${ }^{+}, \mathrm{PB}_{-} \mathrm{NAO}{ }^{-}$, and $\mathrm{PB}-\mathrm{NAO}^{0}$ events (as defined in section 2) and the PCs of the EOF1, EOF2, and EOF3 modes of North American SAT with and without the time scales of 9 years or longer included during 1950-2017. All data were linearly detrended. Numbers in bold are statistically significant at the $10 \%$ level.

\begin{tabular}{lccc}
\hline \hline \multirow{2}{*}{$\begin{array}{c}\text { Correlation } \\
\text { coefficient }\end{array}$} & \multicolumn{3}{c}{ Event } \\
\cline { 2 - 4 } & PB-NAO $^{+}$ & PB-NAO $^{-}$ & PB-NAO $^{0}$ \\
& \multicolumn{4}{c}{ With the time scales of 9 years or longer } \\
included \\
SAT PC1 & -0.180 & $\mathbf{0 . 4 2 0}$ & $\mathbf{0 . 2 2 1}$ \\
SAT PC2 & 0.130 & $\mathbf{- 0 . 2 5 4}$ & -0.170 \\
SAT PC3 & $\mathbf{0 . 5 8 1}$ & $\mathbf{- 0 . 2 3 1}$ & -0.003 \\
& Without the time scales of 9 years or longer \\
& \multicolumn{3}{c}{ included } \\
SAT PC1 & -0.180 & $\mathbf{0 . 3 1}$ & 0.10 \\
SAT PC2 & 0.03 & -0.17 & 0.02 \\
SAT PC3 & $\mathbf{0 . 5 1}$ & $\mathbf{- 0 . 3 2}$ & 0.003 \\
\hline
\end{tabular}

It is found that the interannual SAT EOF1 mode corresponds to an ENSO-like SST anomaly pattern in the Pacific and a weak North Atlantic warm-cold-warm SST tripole pattern (Fig. 11a), whereas the SAT CNWS dipole as EOF3 corresponds to a positive North Pacific mode $\left(\mathrm{NPM}^{+}\right)$(Fig. 11c) (Deser and Blackmon 1995; Hartmann 2015; Peng et al. 2018) and a North Atlantic cold-warm-cold SST tripole pattern. The SST pattern associated with SAT EOF3 (Fig. 11c) also shows a warm anomaly in the northeastern Pacific resembling a Pacific warm blob together with an Atlantic cold blob (Liang et al. 2017; Loeb et al. 2018) or a North Pacific Victoria mode (Ding et al. 2015) and a weak La Niña-like cold anomaly in the Pacific. It appears that the northeastern Pacific SST plays a more important role in the SAT EOF3 mode than the tropical Pacific SST. Thus, the regression patterns in Fig. 11 suggest that while the SAT WWCE and CNWS dipoles over North America are directly related to atmospheric circulation patterns over the North Pacific and North Atlantic, they are also related to the Pacific ENSO-like SST mode, NPM and the North Atlantic SST tripole through atmospheric circulation pattern changes. Because the phase of the NAO has been shown to be associated with the North Atlantic SST tripole (Czaja and Frankignoul 2002), in this paper we do not further examine the influence of the North Atlantic SST tripole on the phase of the NAO.

Although the ENSO cycle can be approximately represented by the Niño-3.4 index or SOI, one cannot obtain the time series of the NPM from the existing indices. In this case, it is helpful to use the PC (PC1 and PC2) time series of the EOF1 and EOF2 modes of detrended winter SST anomalies over the Pacific basin $\left(40^{\circ} \mathrm{S}-60^{\circ} \mathrm{N}, 120^{\circ} \mathrm{E}-\right.$ $90^{\circ} \mathrm{W}$ ) to describe the temporal variations of the ENSO and NPM. The calculation shows that the PC1 (PC2) time series of the Pacific SST anomaly has a correlation of 0.9 (0.26) with the Niño-3.4 index (not shown), but -0.81 $(-0.27)$ with the SOI (not shown), thus suggesting that the SST PC1 time series can be considered as an ENSO index. Moreover, the time scales of the SST EOF1 and EOF2 time series with periods longer than 9 years are removed to reflect the interannual variations of the ENSO and NPM. Here, we show the interannual variations of the EOF1 and EOF2 modes of winter SST anomalies over the Pacific basin $\left(40^{\circ} \mathrm{S}-60^{\circ} \mathrm{N}, 120^{\circ} \mathrm{E}-\right.$ $90^{\circ} \mathrm{W}$ ) and their corresponding $\mathrm{PC} 1$ and $\mathrm{PC} 2$ time series in Fig. 12. It is found that the interannual NPM has a footprint of the ENSO signal, whose $\mathrm{NPM}^{+}$corresponds to a La Niña-like cold east Pacific (Fig. 12d). A significant difference with the La Niña-like mode (the reversed pattern of Fig. 12c) is that for the $\mathrm{NPM}^{+}$there is a strong warm SST anomaly north of $40^{\circ} \mathrm{N}$, but the cold SST anomaly is weak in the east equatorial Pacific (Fig. 12d). Of course, some differences between Figs. 11c and 12d are found because the regressed SST pattern obtained in Fig. 11c is based on the SAT PC3 time series whose variability also depends on other factors such as the NAO, North Atlantic SST and so on.

We also calculated the correlation coefficients of the SAT EOF1, EOF2, and EOF3 modes with the Pacific SST EOF1 and EOF2 modes for the time scales longer than 9 years included and excluded, as shown in Table 2. It is found that while the SAT EOF1 mode (i.e., WWCE dipole) has a significant positive correlation of 0.354 $(p<0.05)$ or $0.464(p<0.01)$ with the ENSO-like mode or NPM, the SAT EOF3 mode (i.e., CNWS dipole) shows a significant positive correlation of $0.37(p<0.05)$ with the NPM (Table 2, top). However, on interannual time scales without the periods longer than 9 years (Table 2, bottom), the SAT EOF3 mode has an insignificant correlation of 0.17 with the NPM, although the correlation coefficient of the SAT EOF1 mode with the ENSO mode or NPM becomes 0.32 or 0.42 . This implies that the SAT CNWS dipole also has a footprint of the decadal SST anomaly and is related to the decadal variability of the Pacific and Atlantic SSTs. This issue will be further examined in another paper.

\section{b. Linkage to the ENSO cycle and the phase of NPM}

Here, we define the value of the Pacific SST PC (e.g., PC1) time series above (below) its $+0.5(-0.5)$ STDs as the positive or negative phase of the ENSO-like mode, whereas the years with the $\mathrm{PC}$ values within -0.5 to 0.5 STDs are referred to as neutral years. The NPM has a similar definition. There are 25 negative (with $67 \mathrm{~PB}$ events), 20 neutral (63 PB events), and 20 positive (47 PB events) winters corresponding to $2.68,3.15$, and 

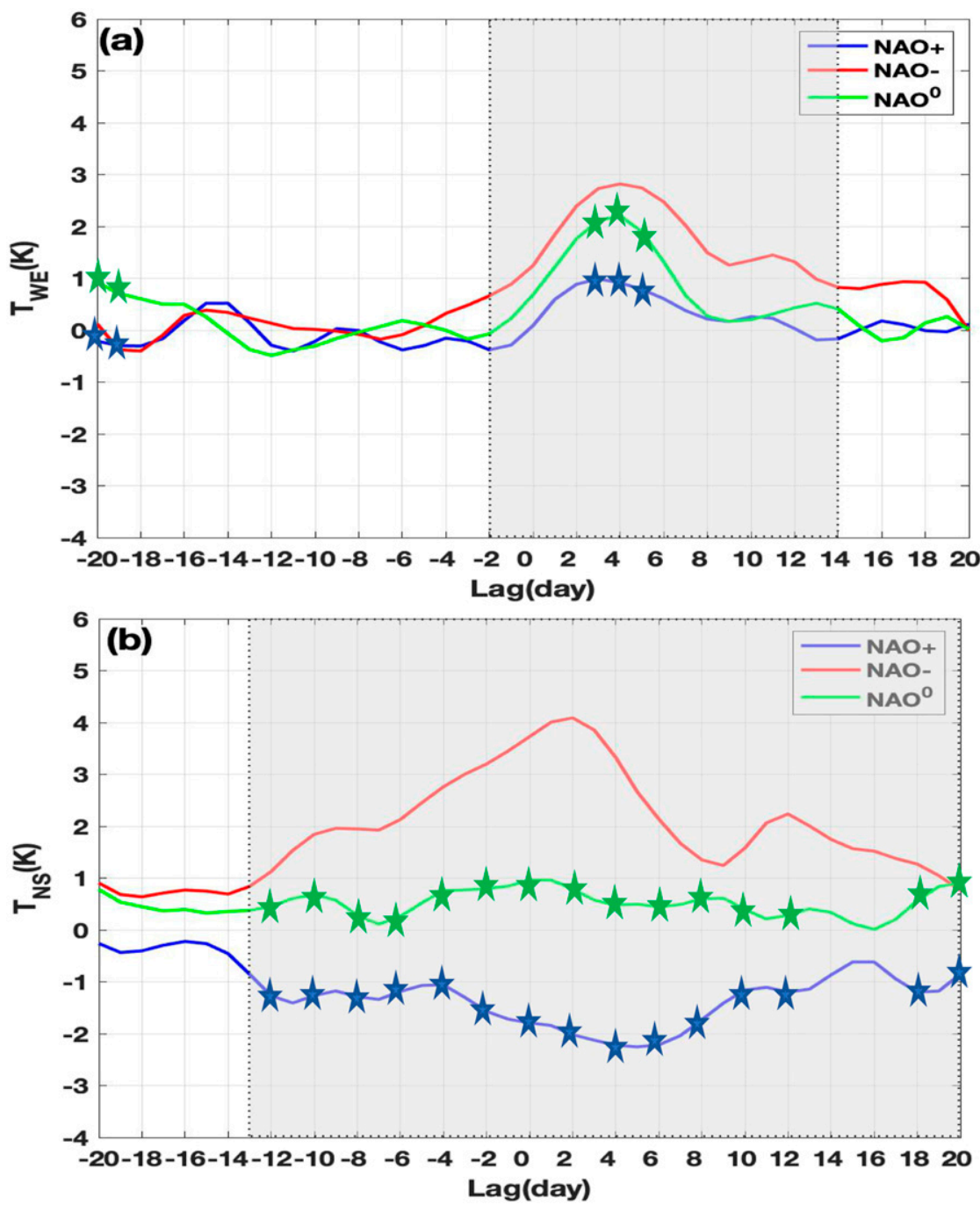

FIG. 10. Time series of the composite daily (a) $T_{W E}$ and (b) $T_{N S}$ indices of North American SAT dipoles for the PB-NAO ${ }^{+}$(blue line), $\mathrm{PB}-N A O^{-}$(red line), and $\mathrm{PB}^{-N A O}{ }^{0}$ (green line) events during 1950-2017 winters, where lag 0 denotes the day of the $\mathrm{PB}$ peak. The gray shading denotes the difference between the $\mathrm{NAO}^{+}$and $\mathrm{NAO}^{-}$being significant at the $95 \%$ confidence level based on a test using 10000 Monte Carlo simulations, whereas the star represents the difference between the $\mathrm{NAO}^{+}$and $\mathrm{NAO}^{0}$ being significant.

2.35 PB events per winter in terms for the ENSO-like (PC1) mode, whereas there are 18 negative (with $39 \mathrm{~PB}$ events), 43 neutral (108 PB events), and 20 positive (71 $\mathrm{PB}$ events) winters corresponding to $2.17,2.51$, and 3.55 PB events per winter in terms for the NPM (PC2). Although the PB events are slightly more frequent during the La Niña winter than during the El Niño winter, more frequent $\mathrm{PB}$ events are seen during the neutral years. Thus, ENSO has a weak influence on PB. We also see that the $\mathrm{PB}$ events are most frequent during the $\mathrm{NPM}^{+}$winter, suggesting that $\mathrm{NPM}^{+}$favors the occurrence of $\mathrm{PB}$ events. This leads to a higher frequency of $\mathrm{PB}$ events during the $\mathrm{NPM}^{+}$, even though the regressed SST anomaly onto the SAT PC3 (Fig. 11c) is a mixed SST mode of the La Niña-like SST mode corresponding to a warm blob in the North Pacific near $40^{\circ} \mathrm{N}$ and cold SSTs in the eastern tropical Pacific and the $\mathrm{NPM}^{+}$mode.

Figures 13a-f show the time-mean composite of daily Z500 and SAT anomalies averaged from lag -10 to 10 days (lag 0 denotes the day of the PB peak) of PB events during the winters with the different phases of the ENSO-like mode and NPM. Overall, a clear SAT WWCE dipole can be seen over North America for the three phases of NPM (Figs. 13d-f), but it differs among the ENSO phases (Figs. 13a-c). While the SAT WWCE 
(a)

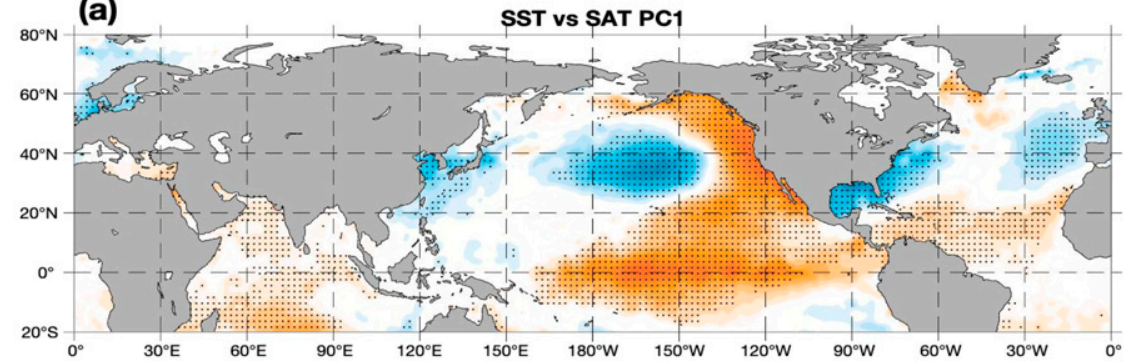

(b)

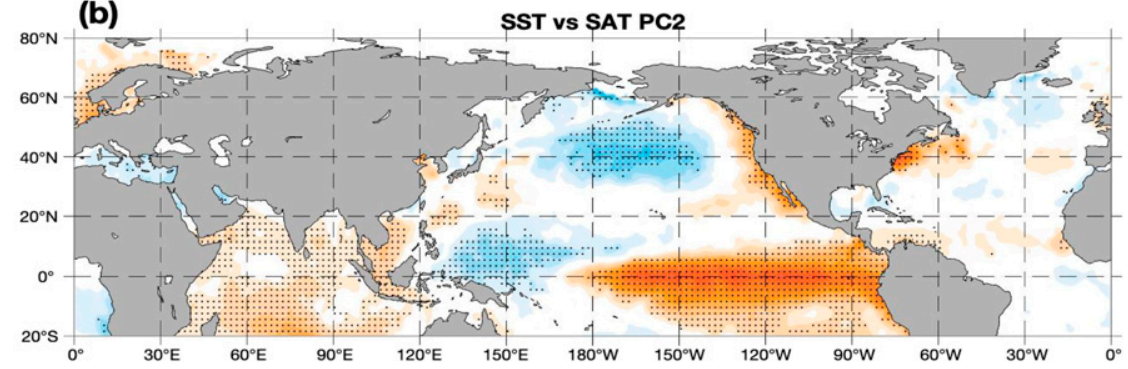

(c)

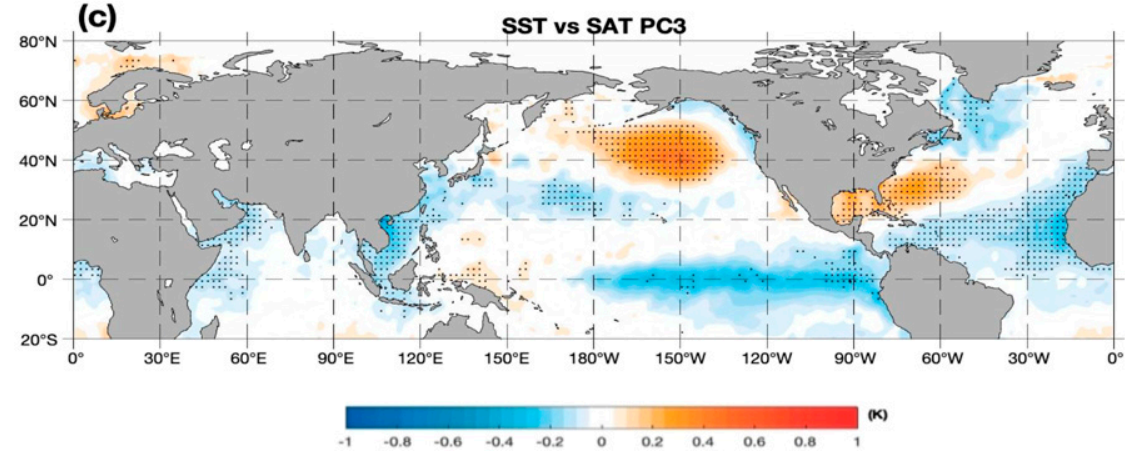

FIG. 11. Regressed interannual DJF-mean SST anomalies against the corresponding PC1, PC2, and PC3 time series of interannual EOF1, EOF2, and EOF3 modes of the North American SAT. The interannual time scale represents the case without the periods longer than 9 years. The dots indicate the regions above the $95 \%$ confidence level based on a two-sided Student's $t$ test.

dipole is strong in the El Niño winter composite (Fig. 13c), the SAT CNWS dipole becomes more evident for the La Niña winter composite (Fig. 13a). Thus, the El Niño-like (La Niña-like) SST mode tends to favor the generation of the WWCE (CNWS) dipole over North America. It is also easy to see from Fig. 12 that the 2013/ 14 winter corresponds to a mixture of a La Niña mode and an $\mathrm{NPM}^{+}$with equal amplitudes (Figs. 12a,b) because their index can reach -0.5 and 0.5 STDs, whereas the 2010/11 winter corresponds to a strong La Niña mode and a weak $\mathrm{NPM}^{+}$(Figs. 12a,b).

\section{c. North American SAT dipole patterns and their linkages to $P B$ and $N A O$}

To understand why the WWCE (CNWS) SAT dipole is associated with ENSO and NPM, we further calculated the frequencies (event number) of the PB-NAO ${ }^{+}, \mathrm{PB}-$ $\mathrm{NAO}^{-}$, and $\mathrm{PB}-\mathrm{NAO}^{0}$ events for different phases of the ENSO cycle and NPM. It is found that there are $35(52 \%)$ $\mathrm{PB}^{-N A O}{ }^{+}, 15$ (23\%) PB-NAO ${ }^{-}$, and 17 (25\%) PB$\mathrm{NAO}^{0}$ events during the La Niña winters and $16(34 \%)$ $\mathrm{PB}^{-N A O}{ }^{+}, 18$ (38\%) PB-NAO ${ }^{-}$, and 13 (28\%) PB$\mathrm{NAO}^{0}$ events during the El Niño winters as well as 29 (46\%) PB-NAO ${ }^{+}, 15$ (24\%) PB-NAO ${ }^{-}$, and 19 (30\%) $\mathrm{PB}^{-N A O^{0}}$ during the neutral winters. Clearly, $\mathrm{PB}-\mathrm{NAO}^{+}$ events are more frequent during the La Niña winters than during the El Niño winters. The opposite is true for the $\mathrm{PB}-\mathrm{NAO}^{-}$events. Further calculations showed that the difference of the $\mathrm{PB}-\mathrm{NAO}^{+}$or $\mathrm{PB}^{-N A O}{ }^{-}$ events between La Niña and El Niño winters is statistically significant $(p<0.05)$. Thus, the PB-NAO ${ }^{+}$(PB$\mathrm{NAO}^{-}$) events seem to be favored by the La Niña-like 

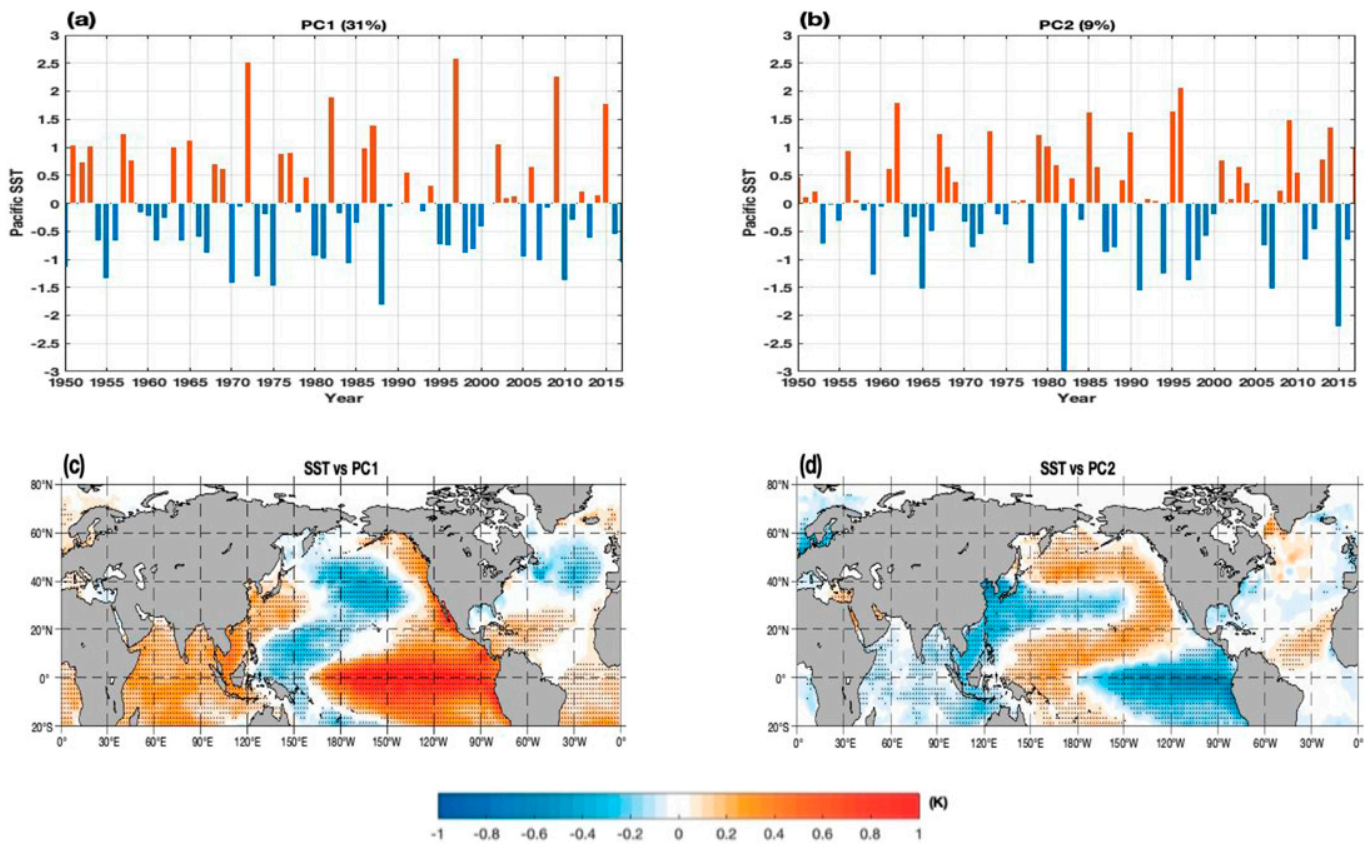

FIG. 12. Time series of the corresponding principal components (PC1 and PC2) of DJF-mean SST anomalies without time scales longer than 9 years for (a) leading and (b) second empirical orthogonal function (EOF1 and EOF2) modes during 1950-2017. Also shown are regression patterns of DJF-mean SST anomalies against the (c) PC1 and (d) PC2 time series without the time scales at least having 9 years. The dots indicate the regions above the $95 \%$ confidence level based on a two-sided Student's $t$ test.

(El Niño-like) Pacific SST anomaly because the La Niñalike (El Niño-like) mode favors the $\mathrm{NAO}^{+}\left(\mathrm{NAO}^{-}\right)$ events ( $\mathrm{Li}$ and Lau 2012).

On the other hand, one cannot use the fact that the PB-NAO ${ }^{+}$is more related to the Pacific La Niña-like SST mode to explain the North American SAT pattern during the 2010/11 winter (Fig. 1c) because the 2010/11 winter corresponds to a very strong $\mathrm{NAO}^{-}$, whereas the La Niña-like SST mode more slightly favors the PB events than the El Niño mode. Maybe the North Atlantic SST also plays a more important role in the 2010/11 North American winter SAT pattern. The North Atlantic and Pacific SSTs and their combined association with the PB with NAO are not discussed here, which will be further reported in another paper.

The time-mean composite of the daily Z500 and SAT anomalies averaged from lag -10 to 10 days of PB$\mathrm{NAO}^{+}, \mathrm{PB}^{-N A O}{ }^{-}$, and PB-NAO ${ }^{0}$ events are shown in Fig. 14 for the three phases of the ENSO cycle. It is found that the composite Z500 anomaly resembles an $\mathrm{AO}^{-}$during the El Niño winters (Fig. 14h) more than during the La Niña winters (Fig. 14b). While a strong CNWS SAT dipole can occur over eastern North America during PB-NAO ${ }^{+}$events (Figs. 14a,g), its cold anomaly tends to occur at lower latitudes during the $\mathrm{La}$ Niña winters (Fig. 14a) and has a relatively large projection onto the SAT WWCE dipole compared to that during the El Niño-like winters (Fig. 14g). Such a feature may be related to a more zonal wave train during the La Niña winters (Fig. 14a). The SAT WWCE dipole over North America is strong during the PB-NAO ${ }^{-}$ events (Figs. 14b,e,h) but relatively weak during the PB$\mathrm{NAO}^{0}$ events (Figs. 14c,f,i). We also note that the PB-NAO ${ }^{0}$ in Fig. 14i essentially corresponds to a weak $\mathrm{PB}$ and a weak $\mathrm{NAO}^{-}$. The above results lead us to infer

TABLE 2. Correlation coefficients between the PCs of the three leading EOFs of North American SAT and the PCs of the EOF1 and EOF2 modes of Pacific SST anomalies with and without the time scales of 9 years or longer included during 1950-2017. All data were linearly detrended. Numbers in bold are statistically significant at the $10 \%$ level.

\begin{tabular}{lcc}
\hline \hline & \multicolumn{2}{c}{ Pacific SST } \\
\cline { 2 - 3 } North American SAT & PC1 (ENSO) & PC2 (NPM) \\
\hline & \multicolumn{2}{c}{ With the time scales of 9 years or } \\
PC1 & $\mathbf{0 . 3 5 4}$ & $\mathbf{0 . 4 6 4}$ \\
PC2 & $\mathbf{0 . 3 5 0}$ & 0.110 \\
PC3 & 0.031 & $\mathbf{0 . 3 7 0}$ \\
& Without the time scales of 9 years \\
PC1 & \multicolumn{2}{c}{ or longer included } \\
PC2 & $\mathbf{0 . 3 2}$ & $\mathbf{0 . 4 2}$ \\
PC3 & $\mathbf{0 . 3 8}$ & $\mathbf{0 . 2 5}$ \\
\hline
\end{tabular}


ENSO
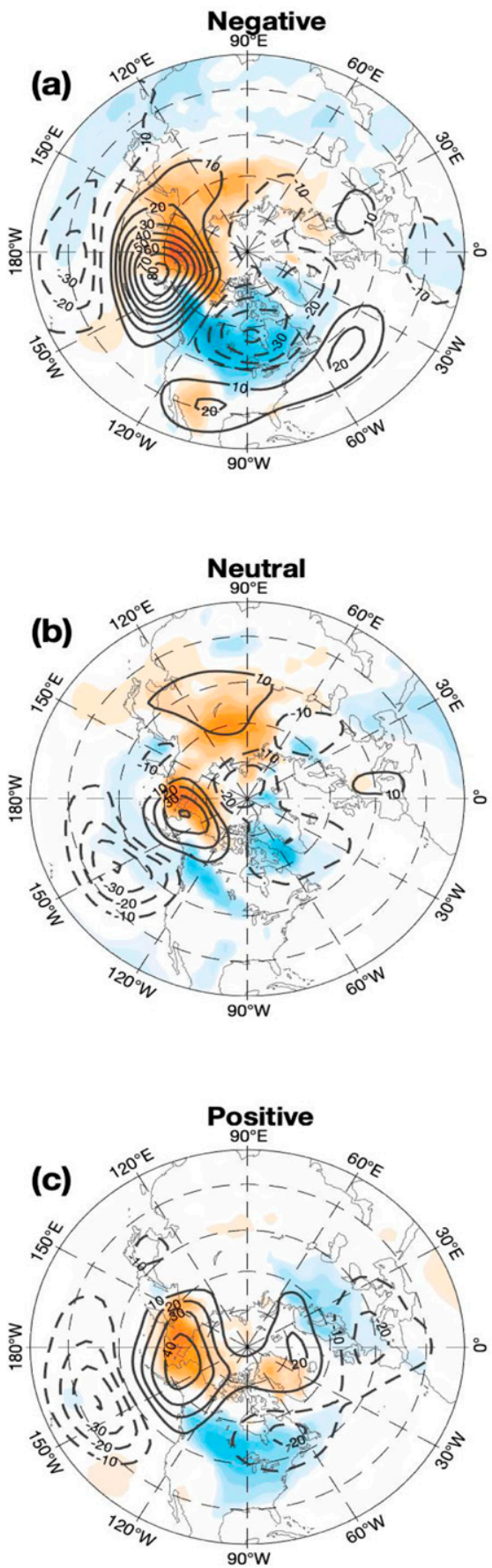

NPM
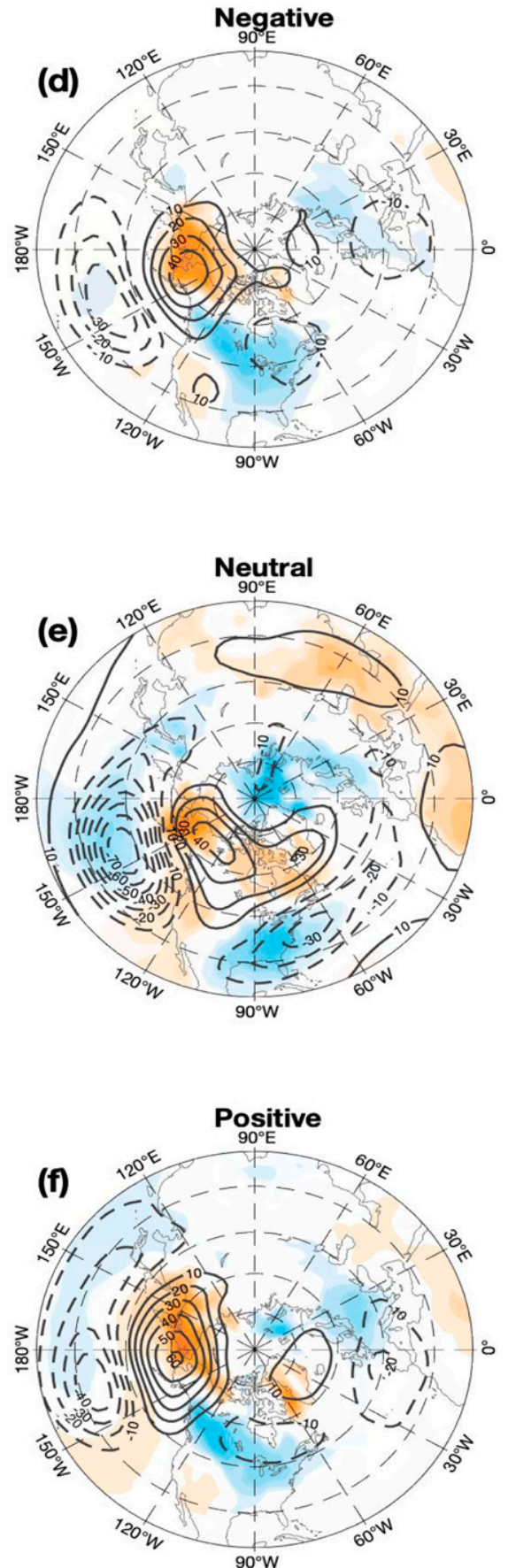

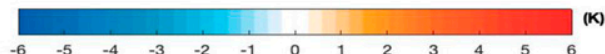

FIG. 13. Time-mean composite daily Z500 and SAT anomalies averaged from lag -10 to 10 days (lag 0 denotes the PB peak) for PB events during (a) 25 negative (La Niña) (67 PB events, (b) 20 neutral (63 PB events), and (c) 20 positive (El Niño) (47 PB events) winters for Pacific SST EOF1 (ENSO) mode and during (d) 18 negative ( $\mathrm{NMP}^{-}$) (39 PB events), (e) 43 neutral (108 PB events), and (f) 20 positive $\left(\mathrm{NMP}^{+}\right)$(71 PB events) winters for the Pacific SST EOF2 mode (NPM). The color shading denotes the region above the $95 \%$ confidence level for a two-sided Student's $t$ test. 
La Niña
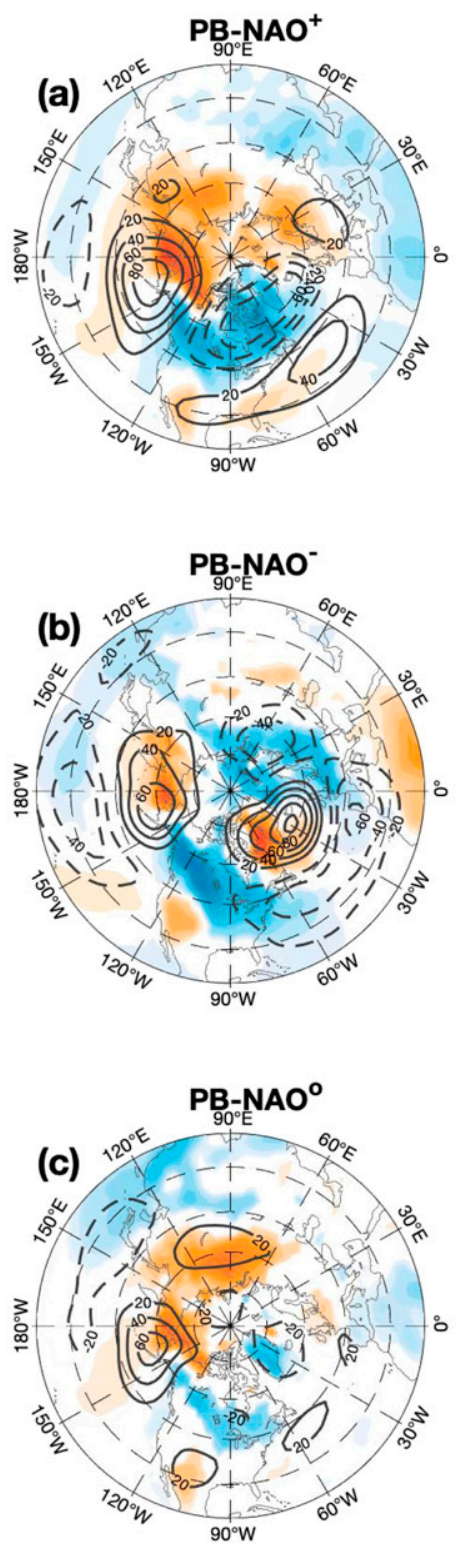

Neutral
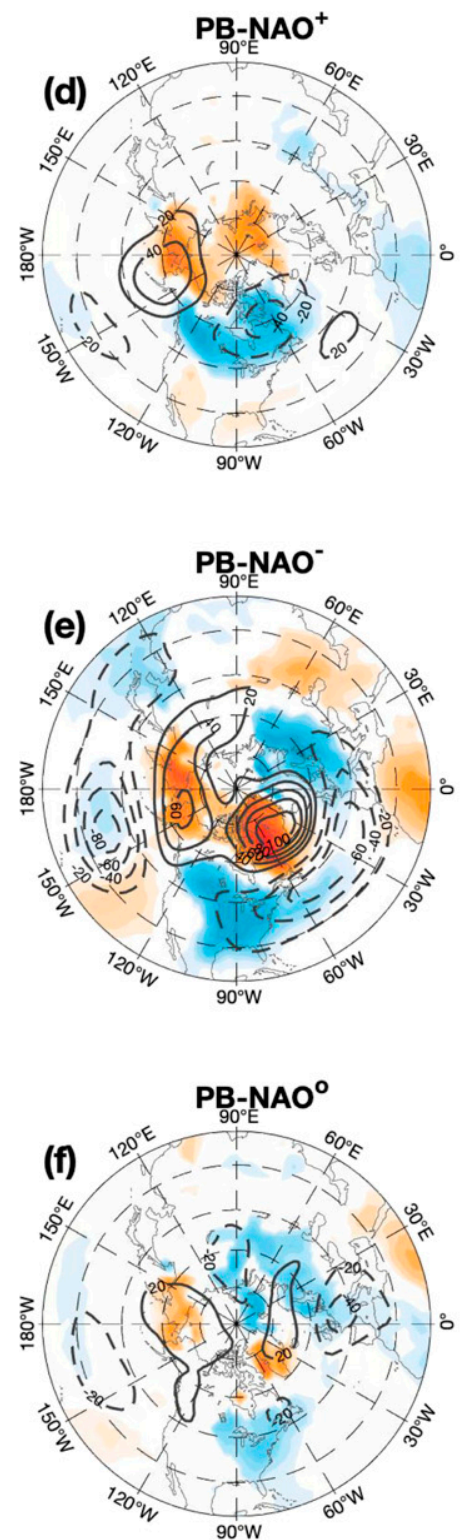

\section{El Niño}
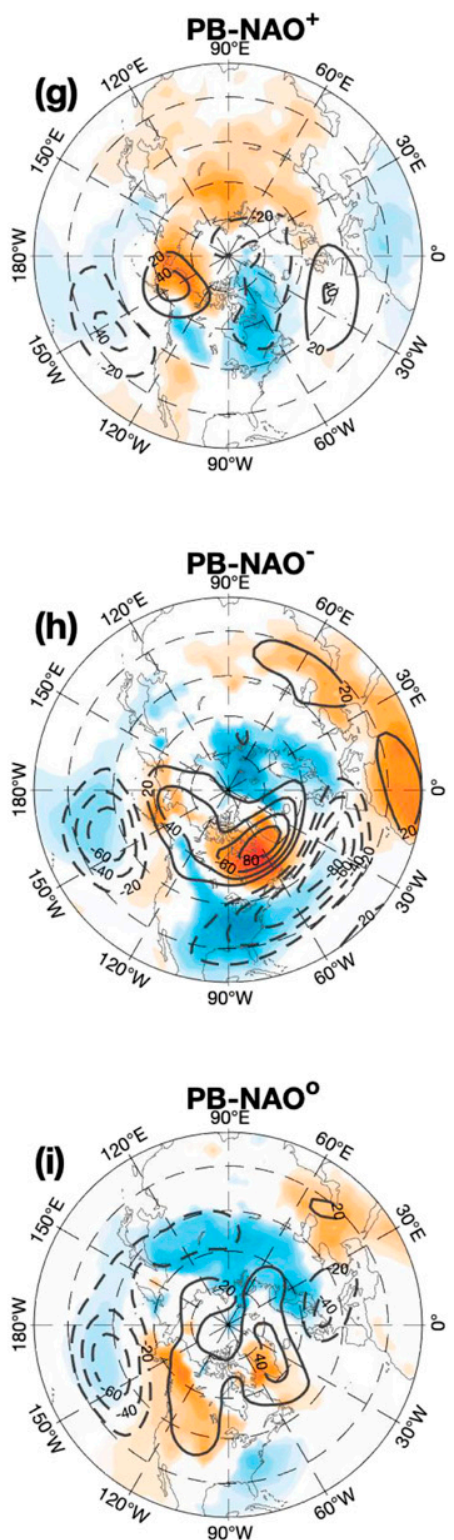

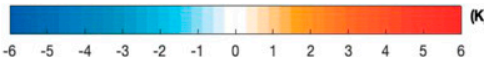

FIG. 14. Time-mean composite daily Z500 and SAT anomalies averaged from lag -10 to 10 days (lag 0 denotes the PB peak) of (top) $\mathrm{PB}_{-} \mathrm{NAO}^{+}$, (middle) PB-NAO ${ }^{-}$, and (bottom) PB-NAO ${ }^{0}$ events for the Pacific (a)-(c) La Niña, (d)-(f) neutral, and (g)-(i) El Niño winters of the Pacific SST EOF1 modes. The color shading represents the area above the $95 \%$ confidence level for a two-sided Student's $t$ test.

that while a strong SAT WWCE (CNWS) dipole over North America can be seen during PB-NAO ${ }^{-}$(PB$\mathrm{NAO}^{+}$) events due to the modulation of the El Niñolike (La Niña-like) SST anomaly, the PB-NAO ${ }^{+}$events are more likely to produce the SAT WWCE dipole during the La Niña winters than during the El Niño winters.

Our calculations further show that for the interannual NPM there were $26(67 \%) \mathrm{PB}^{\mathrm{N} A \mathrm{~N}^{+}}, 6(15 \%)$ PB$\mathrm{NAO}^{-}$, and $7(18 \%) \mathrm{PB}-\mathrm{NAO}^{0}$ events during its negative 
phase $\left(\mathrm{NPM}^{-}\right)$winters and $31(44 \%)$ PB-NAO ${ }^{+}, 24$ (34\%) $\mathrm{PB}-N A O^{-}$, and $16(22 \%) \mathrm{PB}-N A O^{0}$ events during its positive phase $\left(\mathrm{NPM}^{+}\right)$winters, as well as $44(41 \%)$ PB-NAO ${ }^{+}, 29$ (27\%) PB-NAO ${ }^{-}$, and 35 (32\%) PB$\mathrm{NAO}^{0}$ events during its neutral phase $\left(\mathrm{NPM}^{0}\right)$ winters. $\mathrm{A}$ comparison clearly indicates that the $\mathrm{PB}^{-N_{A} \mathrm{O}^{+}}$(PB$\mathrm{NAO}^{-}$) events are more (less) frequent during the $\mathrm{NPM}^{-}$ winters than during the $\mathrm{NPM}^{+}$winters. Our correlation calculations also revealed that only the $\mathrm{PB}-\mathrm{NAO}^{-}$events have a significant positive correlation of $0.35(p<0.05)$ with the NPM (Table 3, bottom) when their time scales longer than 9 years are excluded. However, their correlation coefficient becomes $0.33(p<0.05)$ if when their decadal time scales (longer than 9 years) are included (Table 3a, top).

Figure 15 shows the time-mean composite daily Z500 and SAT anomalies averaged from lag -10 to 10 days of the $\mathrm{PB}-\mathrm{NAO}^{+}, \mathrm{PB}^{-N A O}{ }^{-}$, and $\mathrm{PB}-\mathrm{NAO}^{0}$ events under the different phases of the NPM. One can see that during the $\mathrm{NPM}^{-}$winters the $\mathrm{PB}-\mathrm{NAO}^{-}$events become infrequent while the $\mathrm{PB}-\mathrm{NAO}^{+}$events are very frequent. However, the PB-NAO ${ }^{+}$events do not lead to the WWCE SAT dipole in this case (Fig. 15a). Overall, $\mathrm{NPM}^{-}$does not favor the WWCE SAT dipole over North America. In contrast, strong WWCE dipoles (Fig. 15h) are easily seen over North America due to increased $\mathrm{PB}-\mathrm{NAO}^{-}$events during the $\mathrm{NPM}^{+}$winters. While a strong SAT CNWS dipole can be seen during PB-NAO ${ }^{+}$events, the SAT anomaly has also a large component projecting into the WWCE dipole during the $\mathrm{NPM}^{+}$winters (Fig. $15 \mathrm{~g}$ ) because a more zonal wave train is easily formed through the combination of the $\mathrm{PB}$ and $\mathrm{NAO}^{+}$during the $\mathrm{NPM}^{+}$winters. For the PB-NAO $^{0}$ events (Figs. 15c,f,i), the SAT WWCE and CNWS dipoles are relatively weak. Thus, under the modulation of the $\mathrm{NPM}^{+}$with a warm-cold-warm SST tripole in the North Pacific, both the PB-NAO ${ }^{+}$and PB-NAO ${ }^{-}$ events tend to favor intense SAT WWCE dipoles over North America, although the $\mathrm{PB}-\mathrm{NAO}^{-}$events favor the WWCE dipole more than the PB-NAO ${ }^{+}$events.

\section{Summary and conclusions}

In this paper, we have examined the atmospheric circulation anomaly patterns associated with winter surface air temperature (SAT) anomaly dipole patterns over North America using linearly detrended NCEPNCAR reanalysis daily data from 1950-2017. Our focus was on the potential influences on North American SAT from North Pacific blocking (PB; an anticyclonic anomaly circulation over the North Pacific high latitudes) in combination with different phases of NAO (including neutral NAO cases). We also examined the
TABLE 3. Correlation coefficients between the time series of the PB-NAO ${ }^{+}, \mathrm{PB}_{-} \mathrm{NAO}^{-}$, and $\mathrm{PB}_{-} \mathrm{NAO}^{0}$ events (as defined in section 2) and the PCs of the EOF1, EOF2, and EOF3 modes of Pacific SST anomalies with and without the time scales of 9 years or longer included during 1950-2017. All data were linearly detrended. Numbers in bold are statistically significant at the $10 \%$ level.

\begin{tabular}{lccc}
\hline \hline \multirow{2}{*}{$\begin{array}{c}\text { Correlation } \\
\text { coefficient }\end{array}$} & \multicolumn{3}{c}{ PB event } \\
\cline { 2 - 4 } & PB-NAO $^{+}$ & PB-NAO $^{-}$ & PB-NAO $^{0}$ \\
& With the time scales of 9 years or longer \\
included & \\
Pacific SST PC1 & 0.082 & 0.077 & -0.072 \\
Pacific SST PC2 & 0.166 & $\mathbf{0 . 3 2 9}$ & 0.136 \\
& Without the time scales of 9 years or longer \\
included \\
Pacific SST PC1 & -0.08 & 0.05 & -0.08 \\
Pacific SST PC2 & 0.06 & $\mathbf{0 . 3 5}$ & 0.06 \\
\hline
\end{tabular}

influence of the interannual ( $<9 \mathrm{yr})$ variations of Pacific SSTs on the PB and NAO circulation patterns and North American SAT.

The detrended SAT data show the known warm west/cold east (WWCE) dipole over midlatitude North America as the leading EOF mode, whose temporal variations are correlated with the occurrence frequency of both the PB events over the Pacific and the $\mathrm{NAO}^{-}$ (negative phase NAO) pattern over the North Atlantic. Another SAT mode (EOF3) is characterized by a cold north/warm south (CNWS) dipole over eastern North America and is linked to $\mathrm{PB}$ and $\mathrm{NAO}^{+}$(positive phase NAO). These winter atmospheric circulation and SAT anomaly patterns cannot be identified by the cluster analysis (Figs. 3 and 4). Our composite analysis (Figs. 9d-f) shows that the WWCE dipole is favored by $\mathrm{PB}$ events, and a concurring $\mathrm{NAO}^{-}\left(\mathrm{NAO}^{+}\right)$further enhances (suppresses) such a SAT dipole. In contrast, the CNWS dipole is favored by the $\mathrm{PB}$ events with concurring $\mathrm{NAO}^{+}$, while the combination of $\mathrm{PB}$ with $\mathrm{NAO}^{-}$favors a warm north/cold south dipole over the eastern North America. The $\mathrm{PB}$ and $\mathrm{NAO}^{+}$combined pattern behaves as a high-latitude wave train structure from the North Pacific to the North Atlantic across North America, which projects strongly onto the negative phase of the PacificNorth America $\left(\mathrm{PNA}^{-}\right.$) pattern (Yu and Lin 2019) and has a relatively weak effect on North American midlatitude SAT compared to the case of the $\mathrm{PB}$ with $\mathrm{NAO}^{-}$. The SAT CNWS pattern mainly occurs under the PB$\mathrm{NAO}^{+}$pattern. When PB occurs in the absence of NAO, it does not usually cause a strong north-south SAT dipole over North America. The PB events, in combination of different NAO phases, are also unable to cause a cold west/warm east SAT pattern, whose occurrence conditions (as represented by the negative phase of EOF1 in Fig. 6g) need further investigation. 
NPM- $^{-}$
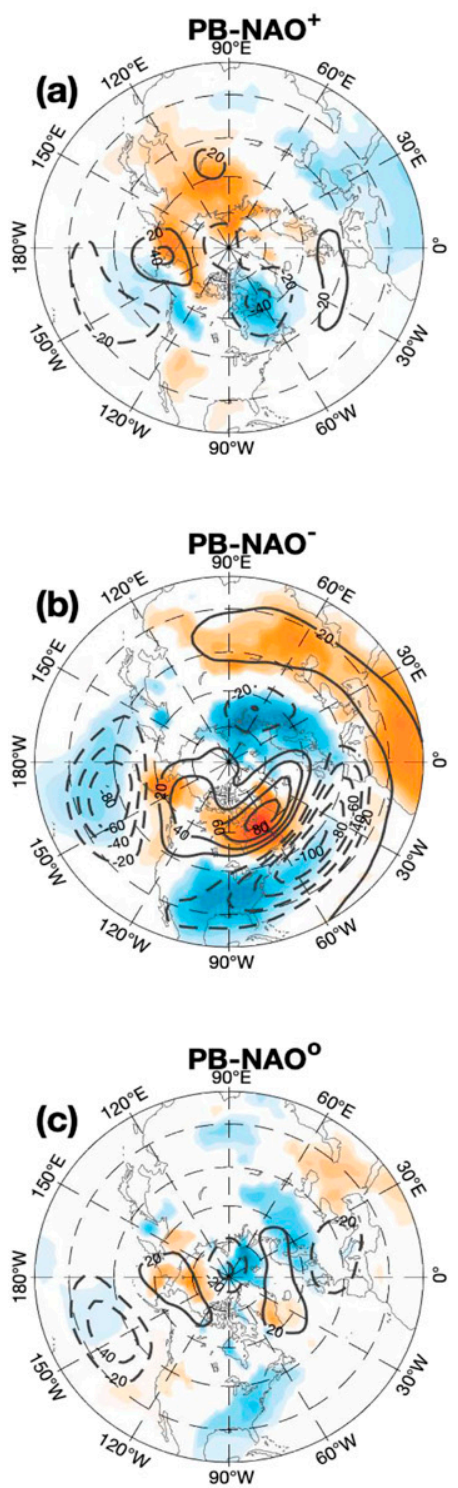

Neutral
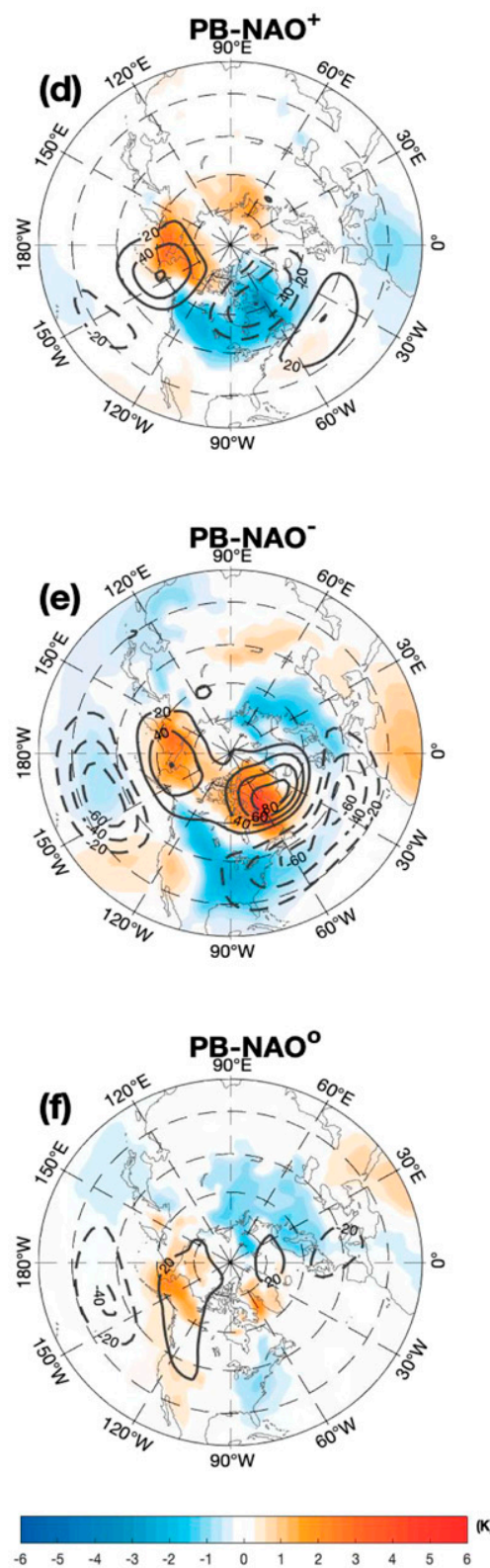
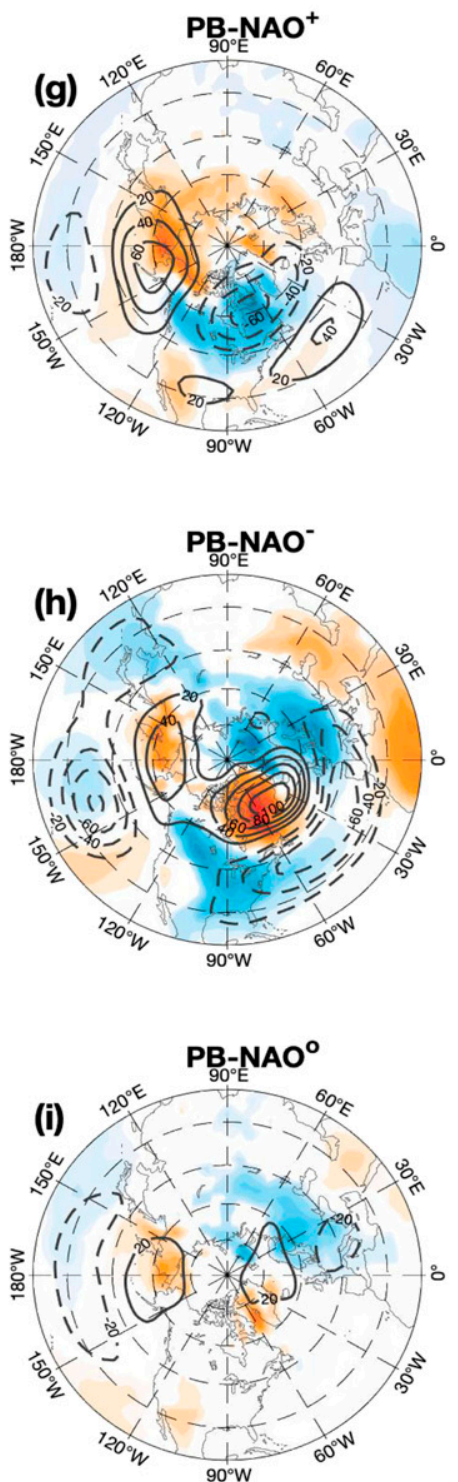

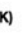

FIG. 15. Time-mean composite daily Z500 and SAT anomalies averaged from lag -10 to 10 days (lag 0 denotes the PB peak) of (top) PB-NAO ${ }^{+}$, (middle) PB-NAO ${ }^{-}$, and (bottom) PB-NAO ${ }^{0}$ events for the (a)-(c) NPM ${ }^{-}$, (d)-(f) neutral, and (g)-(i) NPM ${ }^{+}$winters of Pacific SST EOF2 modes. The color shading represents the area above the $95 \%$ confidence level for a two-sided Student's $t$ test.

The occurrence of the SAT WWCE dipole is positively correlated with the Pacific El Niño-like SST mode and the positive phase of the North Pacific mode $\left(\mathrm{NPM}^{+}\right)$ with a warm-cold-warm SST tripole pattern. The PB$\mathrm{NAO}^{-}$events are favored by the El Niño-like mode or $\mathrm{NPM}^{+}$, whereas the Pacific La Niña-like mode or $\mathrm{NPM}^{-}$ is in favor of PB-NAO ${ }^{+}$events. The $\mathrm{PB}^{-N A O}{ }^{-}$pattern has the most typical subseasonal SAT WWCE dipole especially during the El Niño or $\mathrm{NPM}^{+}$winters. While the $\mathrm{PB}-\mathrm{NAO}^{+}$pattern shows a large CNWS dipole component, it has less projection onto the SAT WWCE dipole during the El Niño or $\mathrm{NPM}^{-}$winters. However, during the La Niña or $\mathrm{NPM}^{+}$winters, the $\mathrm{PB}-\mathrm{NAO}^{+}$pattern can have a relatively large component with the SAT WWCE dipole because a more zonal wave train resulting from the combination of the $\mathrm{PB}$ and $\mathrm{NAO}^{+}$events is more easily 
formed in this case than in other cases. In other words, the $\mathrm{PB}-\mathrm{NAO}^{+}$pattern can lead to the simultaneous appearance of both WWCE and CNWS dipoles over North America during the La Niña and $\mathrm{NPM}^{+}$winters. Comparatively speaking, the NPM seems to play a bigger role in North American SAT variability than ENSO. The above findings differ from many previous studies (Wang et al. 2015; Hartmann 2015; Peng et al. 2018), which have not established a linkage of recent North American winter cold extremes with the Pacific SSTs from a perspective of the PB and NAO combination.

Our conclusions were inferred mainly from composite anomalies, correlations, and regression patterns, which usually do not imply a cause-and-effect relationship on subseasonal and interannual time scales. Nevertheless, the concurring PB/NAO patterns can physically explain the SAT anomalies and thus they may be considered as the atmospheric processes that lead to the SAT anomalies. On the other hand, the concurring SST patterns may partly result from the overlying atmospheric circulation, especially in the extratropics. Thus, one should interpret the SST and PB/NAO patterns as concurring phenomena, rather than the SST being the cause of the PB/NAO patterns, whose main forcing is synoptic eddies. Nevertheless, decadal SST variations in the Pacific and North Atlantic can alter the background lower-boundary conditions of the atmosphere that may influence the frequency of the PB/NAO events and thus the SAT over North America. However, the exact interactions between the decadal or interdecadal SST modes such as the Pacific decadal oscillation (PDO), interdecadal Pacific oscillation (IPO), and Atlantic multidecadal oscillation (AMO) and the PB/NAO patterns require further investigation, which will be reported in another paper.

Acknowledgments. This research was supported by the National Key Research and Development Program of China (2016YFA0601802) and the Chinese Academy of Sciences Strategic Priority Research Program (Grant XDA19070403). A. Dai acknowledges the funding support from the U.S. National Science Foundation (Grant OISE-1743738) and the U.S. National Oceanic and Atmospheric Administration (Award NA18OAR4310425). I. Simmonds acknowledges support from the Australian Research Council (Grant DP160101997).

\section{REFERENCES}

Barnston, A. G., and R. E. Livezey, 1987: Classification, seasonality and persistence of low-frequency atmospheric circulation patterns. Mon. Wea. Rev., 115, 1083-1126, https://doi.org/ 10.1175/1520-0493(1987)115<1083:CSAPOL >2.0.CO;2.
Baxter, S., and S. Nigam, 2015: Key role of the North Pacific Oscillation-west Pacific pattern in generating the extreme 2013/14 North American winter. J. Climate, 28, 8109-8117, https://doi.org/10.1175/JCLI-D-14-00726.1.

Chen, X., and D. Luo, 2017: Arctic sea ice decline and continental cold anomalies: Upstream and downstream effects of Greenland blocking. Geophys. Res. Lett., 44, 3411-3419, https://doi.org/ 10.1002/2016GL072387.

_ North Atlantic sea ice and SST anomalies: The pivotal role of the potential vorticity gradient. J. Climate, 32, 3957-3981, https://doi.org/10.1175/JCLI-D-18-0504.1.

Czaja, A., and C. Frankignoul, 2002: Observed impact of Atlantic SST anomalies on the North Atlantic Oscillation. J. Climate, 15, 606-623, https://doi.org/10.1175/1520-0442(2002)015<0606: OIOASA $>2.0 . \mathrm{CO} ; 2$

Dai, A., 2013: The influence of the inter-decadal Pacific Oscillation on US precipitation during 1923-2010. Climate Dyn., 41, 633646, https://doi.org/10.1007/s00382-012-1446-5.

_ J. C. Fyfe, S.-P. Xie, and X. Dai, 2015: Decadal modulation of global surface temperature by internal climate variability. Nat. Climate Change, 5, 555-559, https://doi.org/10.1038/ nclimate2605.

Deser, D., and M. Blackmon, 1995: On the relationship between tropical and North Pacific sea surface temperature variations J. Climate, 8, 1677-1680, https://doi.org/10.1175/1520-0442(1995) $008<1677$ :OTRBTA $>2.0$. CO;2.

Diao, Y., J. Li, and D. Luo, 2006: A new blocking index and its application: Blocking action in the Northern Hemisphere. J. Climate, 19, 4819-4839, https://doi.org/10.1175/JCLI3886.1.

Ding, R., J. Li, Y.-h. Tseng, and C. Ruan, 2015: Influence of the North Pacific Victoria mode on the Pacific ITCZ summer precipitation. J. Geophys. Res. Atmos., 120, 964-979, https:// doi.org/10.1002/2014JD022364.

Hansen, J., R. Ruedy, M. Sato, and K. Lo, 2010: Global surface temperature change. Rev. Geophys., 48, RG4004, https:// doi.org/10.1029/2010RG000345.

Harnik, N., G. Messori, R. Caballero, and S. B. Feldstein, 2016: The circumglobal North American wave pattern and its relation to cold events in eastern North America. Geophys. Res. Lett., $\mathbf{4 3}$, 11 015-11 023, https://doi.org/10.1002/2016GL070760.

Hartmann, D. L., 2015: Pacific sea surface temperature and the winter of 2014. Geophys. Res. Lett., 42, 1894-1902, https:// doi.org/10.1002/2015GL063083.

Kalnay, E., and Coauthors, 1996: The NCEP/NCAR 40-Year Reanalysis Project. Bull. Amer. Meteor. Soc., 77, 437-471, https:// doi.org/10.1175/1520-0477(1996)077<0437:TNYRP > 2.0.CO;2.

Lee, M.-Y., C.-C. Hong, and H.-H. Hsu, 2015: Compounding effects of warm sea surface temperature and reduced sea ice on the extreme circulation over the extratropical North Pacific and North America during the 2013-2014 boreal winter. Geophys. Res. Lett., 42, 1612-1618, https://doi.org/10.1002/2014GL062956.

Li, Y., and N. Lau, 2012: Impact of ENSO on the atmospheric variability over the North Atlantic in late winter-Role of transient eddies. J. Climate, 25, 320-342, https://doi.org/ 10.1175/JCLI-D-11-00037.1.

Liang, Y., Y. Jin, E. S. Saltzman, and F. Wang, 2017: Linking the tropical Northern Hemisphere pattern to the Pacific warm blob and Atlantic cold blob. J. Climate, 30, 9041-9057, https:// doi.org/10.1175/JCLI-D-17-0149.1.

Lin, H., 2015: Subseasonal variability of North American wintertime surface air temperature. Climate Dyn., 45, 1137-1155, https://doi.org/10.1007/s00382-014-2363-6. 
Linkin, M. E., and S. Nigam, 2008: The North Pacific Oscillationwest Pacific teleconnection pattern: Mature-phase structure and winter impacts. J. Climate, 21, 1979-1997, https://doi.org/ 10.1175/2007JCLI2048.1.

Loeb, N. G., T. J. Tyler, J. R. Norris, H. Wang, and W. Su, 2018: Changes in Earth's energy budget during and after the "pause" in global warming: An observational perspective. Climate, 6, 62, https://doi.org/10.3390/CLI6030062.

Luo, B., D. Luo, L. Wu, L. Zhong, and I. Simmonds, 2017 Atmospheric circulation patterns which promote winter Arctic sea ice decline. Environ. Res. Lett., 12, 054017, https://doi.org/ 10.1088/1748-9326/aa69d0.

— L. Wu, D. Luo, A. Dai, and I. Simmonds, 2019: The winter midlatitude-Arctic interaction: Effects of North Atlantic SST and high-latitude blocking on Arctic sea ice and Eurasian cooling. Climate Dyn., 52, 2981-3004, https://doi.org/10.1007/ s00382-018-4301-5.

Luo, D., 2005: A barotropic envelope Rossby soliton model for block-eddy interaction. Part I: Effect of topography. J. Atmos. Sci., 62, 5-21, https://doi.org/10.1175/1186.1.

— A. Lupo, and H. Wan, 2007: Dynamics of eddy-driven low frequency dipole modes. Part I: A simple model of North Atlantic Oscillations. J. Atmos. Sci., 64, 3-28, https://doi.org/ 10.1175/JAS3818.1.

Michelangeli, P. A., R. Vautard, and B. Legras, 1995: Weather regimes: Recurrence and quasi stationarity. J. Atmos. Sci., 52, 1237-1256, https://doi.org/10.1175/1520-0469(1995)052<1237: WRRAQS $>2.0 . \mathrm{CO} ; 2$

Mo, K. C., J. K. E. Schemm, and S. H. Yoo, 2009: Influence of ENSO and the Atlantic multidecadal oscillation on drought over the United States. J. Climate, 22, 5962-5982, https:// doi.org/10.1175/2009JCLI2966.1.

Nigam, S., B. Guan, and A. Ruiz-Barradas, 2011: Key role of the Atlantic Multidecadal Oscillation in 20th century drought and wet periods over the great plains. Geophys. Res. Lett., 38, L16713, https://doi.org/10.1029/2011GL048650.

Overland, J. E., and M. Wang, 2015: Increased variability in the early winter subarctic North American atmospheric circulation. J. Climate, 28, 7297-7305, https://doi.org/10.1175/JCLI-D-15-0395.1.

Peng, P., A. Kumar, and Z. Z. Hu, 2018: What drove the Pacific and North America climate anomalies in winter 2014/15? Climate Dyn., 51, 2667-2679, https://doi.org/10.1007/s00382-017-4035-9.

- - M. Chen, Z. Hu, and B. Jha, 2019: Was the North American extreme climate in winter 2013/14 a SST forced response? Climate Dyn., 52, 3099-3110, https://doi.org/10.1007/ s00382-018-4314-0.

Rayner, N. A., D. E. Parker, E. B. Horton, C. K. Folland, L. V. Alexander, D. P. Rowell, E. C. Kent, and A. Kaplan, 2003: Global analyses of sea surface temperature, sea ice, and night marine air temperature since the late nineteenth century. J. Geophys. Res., 108, 4407, https://doi.org/10.1029/2002JD002670.

Seager, R., and N. Henderson, 2016: On the role of tropical ocean forcing of the persistent North American west coast ridge of winter 2013/14. J. Climate, 29, 8027-8049, https://doi.org/ 10.1175/JCLI-D-16-0145.1.

, and Coauthors, 2007: Model projections of an imminent transition to a more arid climate in southwestern North. Amer. Sci.,316, 1181-1184, https://doi.org/10.1126/SCIENCE.1139601.
- M. Hoerling, S. Schubert, H. Wang, B. Lyon, A. Kumar, J. Nakamura, and N. N. Henderson, 2015: Causes of the 201114 California drought. J. Climate, 28, 6997-7024, https:// doi.org/10.1175/JCLI-D-14-00860.1.

Singh, D., D. L. Swain, J. S. Mankin, D. E. Horton, L. N. Thomas, B. Rajaratnam, and N. S. Diffenbaugh, 2016: Recent amplification of the North American winter temperature dipole. J. Geophys. Res. Atmos., 121, 9911-9928, https://doi.org/ 10.1002/2016JD025116

Swain, D., D. Horton, D. Singh, and N. S. Diffenbaugh, 2016: Trends in atmospheric patterns conducive to seasonal precipitation and temperature extremes in California. Sci. Adv., 2, e1501344, https://doi.org/10.1126/sciadv.1501344.

Tibaldi, S., and F. Molteni, 1990: On the operational predictability of blocking. Tellus, 42A, 343-365, https://doi.org/10.3402/ tellusa.v42i3.11882.

Ting, M., and H. Wang, 1997: Summertime U.S. precipitation variability and its relation to Pacific sea surface temperature. J. Climate, 10, 1853-1873, https://doi.org/10.1175/ 1520-0442(1997)010<1853:SUSPVA > 2.0.CO;2.

Vigaud, N., A. W. Robertson, and M. K. Tippett, 2018: Predictability of recurrent weather regimes over North America during winter from submonthly reforecasts. Mon. Wea. Rev., 146, 2559-2577, https://doi.org/10.1175/MWR-D-18-0058.1.

Wang, H., and R. Fu, 2000: Winter monthly mean atmospheric anomalies over the North Pacific and North America associated with El Niño SSTs. J. Climate, 13, 3435-3447, https:// doi.org/10.1175/1520-0442(2000)013<3435:WMMAAO > 2.0.CO;2.

Wang, S.-Y. S., L. Hipps, R. R. Gillies, and J. H. Yoon, 2014: Probable causes of the abnormal ridge accompanying the 2013-2014 California drought: ENSO precursor and anthropogenic warming footprint. Geophys. Res. Lett., 41, 32203226, https://doi.org/10.1002/2014GL059748.

, W.-R. Huang, and J.-H. Yoon, 2015: The North American winter "dipole" and extremes activity: A CMIP5 assessment. Atmos. Sci. Lett., 16, 338-345, https://doi.org/10.1002/as12.565.

Xie, J., and M. Zhang, 2017: Role of internal atmospheric variability in the 2015 extreme winter climate over the North American continent. Geophys. Res. Lett., 44, 2464-2471, https://doi.org/10.1002/2017GL072772.

Yu, B., and X. Zhang, 2015: A physical analysis of the severe 2013/ 2014 cold winter in North America. J. Geophys. Res. Atmos., 120, $10149-10165$, https://doi.org/10.1002/2015JD023116. , and H. Lin, 2019: Modification of the wintertime PacificNorth American pattern related North American climate anomalies by the Asian-Bering-North American teleconnection. Climate Dyn., 53, 313-328, https://doi.org/10.1007/ s00382-018-4586-4.

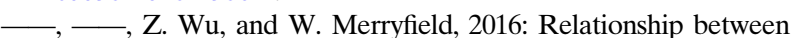
North American winter temperature and large-scale atmospheric circulation anomalies and its decadal variation. Environ. Res. Lett., 11, 074001, https://doi.org/10.1088/1748-9326/11/7/074001.

Zaba, K. D., and D. L. Rudnick, 2016: The 2014-2015 warming anomaly in the Southern California Current System observed by underwater gliders. Geophys. Res. Lett., 43, 1241-1248, https://doi.org/10.1002/2015GL067550. 